\title{
Internal dressings for healing perianal abscess cavities
}

DOI:

10.1002/14651858.CD011193.pub2

\section{Document Version}

Final published version

Link to publication record in Manchester Research Explorer

\section{Citation for published version (APA):}

Smith, S. R., Newton, K., Smith, J., Dumville, J., Iheozor-Ejiofor, Z., Pearce, L., Barrow, P. J., Hancock, L., \& Hill, J. (2016). Internal dressings for healing perianal abscess cavities. The Cochrane database of systematic reviews, 8, [CD011193]. https://doi.org/10.1002/14651858.CD011193.pub2

\section{Published in:}

The Cochrane database of systematic reviews

\section{Citing this paper}

Please note that where the full-text provided on Manchester Research Explorer is the Author Accepted Manuscript or Proof version this may differ from the final Published version. If citing, it is advised that you check and use the publisher's definitive version.

\section{General rights}

Copyright and moral rights for the publications made accessible in the Research Explorer are retained by the authors and/or other copyright owners and it is a condition of accessing publications that users recognise and abide by the legal requirements associated with these rights.

\section{Takedown policy}

If you believe that this document breaches copyright please refer to the University of Manchester's Takedown Procedures [http://man.ac.uk/04Y6Bo] or contact uml.scholarlycommunications@manchester.ac.uk providing relevant details, so we can investigate your claim.

\section{OPEN ACCESS}




\section{(E) Cochrane Library}

Cochrane Database of Systematic Reviews

\section{Internal dressings for healing perianal abscess cavities (Review)}

Smith SR, Newton K, Smith JA, Dumville JC, Iheozor-Ejiofor Z, Pearce LE, Barrow PJ, Hancock L, Hill J

Smith SR, Newton K, Smith JA, Dumville JC, Iheozor-Ejiofor Z, Pearce LE, Barrow PJ, Hancock L, Hill J.

Internal dressings for healing perianal abscess cavities.

Cochrane Database of Systematic Reviews 2016, Issue 8. Art. No.: CD011193.

DOI: 10.1002/14651858.CD011193.pub2.

www.cochranelibrary.com 
TABLE OF CONTENTS

HEADER . . . . . . . . . . . . . . . . . . . . . . . . . . . . . . . . . . . . . . . 1

ABSTRACT . . . . . . . . . . . . . . . . . . . . . . . . . . . . . . . . . . . . . . . . 1

PLAIN LANGUAGE SUMMARY . . . . . . . . . . . . . . . . . . . . . . . . . . . . . . . . . . . .

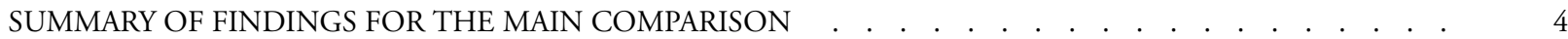

BACKGROUND . . . . . . . . . . . . . . . . . . . . . . . . . . . . . . . . . . . . 6

OBJECTIVES . . . . . . . . . . . . . . . . . . . . . . . . . . . . . . . . . . . . . . . . . . . . . .

METHODS . . . . . . . . . . . . . . . . . . . . . . . . . . . . . . . . . . . . . .

Figure 1. . . . . . . . . . . . . . . . . . . . . . . . . . . . . . . . . . . 10

RESULTS . . . . . . . . . . . . . . . . . . . . . . . . . . . . . . . . . . . . . 12

Figure 2. . . . . . . . . . . . . . . . . . . . . . . . . . . . . . . . . . . . . . 14

DISCUSSION . . . . . . . . . . . . . . . . . . . . . . . . . . . . . . . . . . . . .

AUTHORS' CONCLUSIONS . . . . . . . . . . . . . . . . . . . . . . . . . . . . . . . . . . . . . .

ACKNOWLEDGEMENTS . . . . . . . . . . . . . . . . . . . . . . . . . . . . . . . . . . . . . . . . 18

REFERENCES . . . . . . . . . . . . . . . . . . . . . . . . . . . . . . . . . . . . . . . 18

CHARACTERISTICS OF STUDIES . . . . . . . . . . . . . . . . . . . . . . . . . . . . . . . . . . . . . .

DATA AND ANALYSES . . . . . . . . . . . . . . . . . . . . . . . . . . . . . . . . . . . . 31

Analysis 1.1. Comparison 1 Packing compared with no packing, Outcome 1 Time to wound healing. . . . . . . 31

Analysis 1.2. Comparison 1 Packing compared with no packing, Outcome 2 Fistula formation. . . . . . . . . . . 32

Analysis 1.3. Comparison 1 Packing compared with no packing, Outcome 3 Abscess recurrence. . . . . . . . . 32

APPENDICES . . . . . . . . . . . . . . . . . . . . . . . . . . . . . . . . . . . . . 32

CONTRIBUTIONS OF AUTHORS . . . . . . . . . . . . . . . . . . . . . . . . . . . . . . . . . . . . . . . . . . .

DECLARATIONS OF INTEREST . . . . . . . . . . . . . . . . . . . . . . . . . . . . . . . . . . 40

SOURCES OF SUPPORT . . . . . . . . . . . . . . . . . . . . . . . . . . . . . . . . . . . . 40

DIFFERENCES BETWEEN PROTOCOL AND REVIEW . . . . . . . . . . . . . . . . . . . . . . 41

INDEX TERMS . . . . . . . . . . . . . . . . . . . . . . . . . . . . . . . . . . . . . 41

Internal dressings for healing perianal abscess cavities (Review)

Copyright $\odot 2016$ The Cochrane Collaboration. Published by John Wiley \& Sons, Ltd. 


\title{
[Intervention Review]
}

\section{Internal dressings for healing perianal abscess cavities}

\author{
Stella R Smith ${ }^{1}$, Katy Newton ${ }^{1}$, Jennifer A Smith ${ }^{1}$, Jo C Dumville ${ }^{2}$, Zipporah Iheozor-Ejiofor ${ }^{3}$, Lyndsay E Pearce ${ }^{4}$, Paul J Barrow ${ }^{1}$, \\ Laura Hancock ${ }^{1}$, James Hill ${ }^{4}$ \\ ${ }^{1}$ General Surgery, North Western Deanery, Manchester, UK. ${ }^{2}$ School of Nursing, Midwifery and Social Work, University of Manchester, \\ Manchester, UK. ${ }^{3}$ Cochrane Wounds Group, University of Manchester, Manchester, UK. ${ }^{4}$ Department of Surgery, Central Manchester \\ University Hospitals NHS Foundation Trust, Manchester, UK
}

Contact address: Stella R Smith, General Surgery, North Western Deanery, 4th Floor, 3 Piccadilly, Manchester, M1 3BN, UK. Stellasmith5@hotmail.com.

Editorial group: Cochrane Wounds Group.

Publication status and date: New, published in Issue 8, 2016.

Review content assessed as up-to-date: 17 May 2016.

Citation: Smith SR, Newton K, Smith JA, Dumville JC, Iheozor-Ejiofor Z, Pearce LE, Barrow PJ, Hancock L, Hill J. Internal dressings for healing perianal abscess cavities. Cochrane Database of Systematic Reviews 2016, Issue 8. Art. No.: CD011193. DOI: 10.1002/14651858.CD011193.pub2.

Copyright (C) 2016 The Cochrane Collaboration. Published by John Wiley \& Sons, Ltd.

\begin{abstract}
A B S T R A C T
Background

A perianal abscess is a collection of pus under the skin, around the anus. It usually occurs due to an infection of an anal gland. In the UK, the annual incidence is 40 per 100,000 of the adult population, and the standard treatment is admission to hospital for incision and drainage under general anaesthetic. Following drainage of the pus, an internal dressing (pack) is placed into the cavity to stop bleeding. Common practice is for community nursing teams to change the pack regularly until the cavity heals. Some practitioners in the USA and Australia make a small stab incision under local anaesthetic and place a catheter into the cavity which drains into an external dressing. It is removed when it stops draining. Elsewhere in the USA, simple drainage is performed in an outpatient setting under local anaesthetic.
\end{abstract}

\section{Objectives}

To assess the effects of internal dressings in healing wound cavities resulting from drainage of perianal abscesses.

\section{Search methods}

In May 2016 we searched: The Cochrane Wounds Specialised Register; The Cochrane Central Register of Controlled Trials (CENTRAL) (The Cochrane Library); Ovid MEDLINE; Ovid MEDLINE (In-Process \& Other Non-Indexed Citations); Ovid EMBASE and EBSCO CINAHL Plus. We also searched clinical trial registries to identify ongoing and unpublished studies, and searched reference lists of relevant reports to identify additional studies. We did not restrict studies with respect to language, date of publication, or study setting.

\section{Selection criteria}

Published or unpublished randomised controlled trials (RCTs) comparing any type of internal dressing (packing) used in the postoperative management of perianal abscess cavities with alternative treatments or different types of internal dressing.

\section{Data collection and analysis}

Two review authors independently performed study selection, risk of bias assessment, and data extraction.

Internal dressings for healing perianal abscess cavities (Review)

Copyright $\odot 2016$ The Cochrane Collaboration. Published by John Wiley \& Sons, Ltd. 


\section{Main results}

We included two studies, with a total of 64 randomised participants (50 and 14 participants) aged 18 years or over, with a perianal abscess. In both studies, participants were enrolled on the first post-operative day and randomised to continued packing by community district nursing teams or to no packing. Participants in the non-packing group managed their own wounds in the community and used absorbant dressings to cover the area. Fortnightly follow-up was undertaken until the cavity closed and the skin re-epithelialised, which constituted healing. For non-attenders, telephone follow-up was conducted.

Both studies were at high risk of bias due to risk of attrition, performance and detection bias.

It was not possible to pool the two studies for the outcome of time to healing. It is unclear whether continued post-operative packing of the cavity of perianal abscesses affects time to complete healing. One study reported a mean time to wound healing of 26.8 days (95\% confidence interval (CI) 22.7 to 30.7) in the packing group and 19.5 days (95\% CI 13.6 to 25.4 ) in the non-packing group (it was not clear if all participants healed). We re-analysed the data and found no clear difference in the time to healing (7.30 days longer in the packing group, $95 \%$ CI -2.24 to $16.84 ; 14$ participants). This was assessed as very low quality evidence (downgraded three levels for very serious imprecision and serious risk of bias). The second study reported a median time to complete wound healing of 24.5 days (range 10 to 150 days) in the packing group and 21 days (range 8 to 90 days) in the non-packed group. There was insufficient information to be able to recreate the analysis and the original analysis was inappropriate (did not account for censoring). This second study also provided very low quality evidence (downgraded four levels for serious risk of bias, serious indirectness and very serious imprecision).

There was very low quality evidence (downgraded for risk of bias, indirectness and imprecision) of no difference in wound pain scores at the initial dressing change. Both studies also reported patients' retrospective judgement of wound pain over the preceding two weeks (visual analogue scale, VAS) as lower for the non-packed group (2; both studies) compared with the packed group (0; both studies); (very low quality evidence) but we have been unable to reproduce these analyses as no variance data were published.

There was no clear evidence of a difference in the number of post-operative fistulae detected between the packed and non-packed groups (risk ratio (RR) 2.31, 95\% CIs 0.56 to $9.45, \mathrm{I}^{2}=0 \%$ ) (very low quality evidence downgraded three levels for very serious imprecision and serious risk of bias).

There was no clear evidence of a difference in the number of abscess recurrences between the packed and non-packed groups over the variable follow-up periods (RR $0.72,95 \%$ CI 0.22 to $2.37, \mathrm{I}^{2}=0 \%$ ) (very low quality evidence downgraded three levels for serious risk of bias and very serious imprecision).

No study reported participant health-related quality of life/health status, incontinence rates, time to return to work or normal function, resource use in terms of number of dressing changes or visits to a nurse, or change in wound size.

\section{Authors' conclusions}

It is unclear whether using internal dressings (packing) for the healing of perianal abscess cavities influences time to healing, wound pain, development of fistulae, abscess recurrence or other outcomes. Despite this absence of evidence, the practice of packing abscess cavities is commonplace. Given the lack of high quality evidence, decisions to pack may be based on local practices or patient preferences. Further clinical research is needed to assess the effects and patient experience of packing.

\section{PLAIN LANGUAGE SUMMARY}

\section{Internal dressings for healing perianal abscess cavities}

\section{What are perianal abscesses and how are they treated?}

A perianal abscess is a collection of pus under the skin around the anus (back passage); perianal abscesses are common, and usually due to an infection in an anal gland. In the UK, the standard treatment is to have an operation under anaesthetic to cut the skin and drain the pus. This prevents the infection spreading and relieves pain in the affected area. An internal dressing (otherwise known as a "pack") is placed inside the abscess cavity, initially to stop bleeding. The pack is changed by nurses in the community regularly until the cavity has healed. It is thought that packing the cavity reduces the chance of the abscess recurring.

Some patients go on to develop a fistula after a perianal abscess. A fistula is an abnormal communication between the anus and the skin next to it and a small hole next to the anus discharges pus intermittently. Fistulae can take many months and several operations 
to heal. This review aims to assess the effects of packs on healing perianal abscess cavities, particularly the time it took for the cavities to heal, and the amount of pain patients experienced.

\section{What we found}

After extensive searching to find relevant studies, we found only two randomised controlled trials (RCTs) that were eligible for this review (RCTs provide more robust results than other trial types). The studies were small with a total of 64 participants randomised, all over 18 years of age, with a perianal abscess. In the studies, participants received either packing by community nursing teams or no packing. Participants in the non-packing group managed their own wounds by using absorbant dressings to cover the area with no internal dressing. Participants were seen fortnightly until the cavity had healed.

It is not clear whether time to complete wound healing is affected by packing of cavity (and what evidence exists is very low quality). There was very low quality evidence that packing made no difference to wound pain at the first dressing change. There was very low quality evidence that on judging the wound pain over the preceding two weeks, participants in the packing group had experienced more pain that those in the non-packing group.

It is not clear whether packing or not affects the number of post-operative fistulae or abscess recurrences.

We did not find any RCTs that compared participant health-related quality of life/health status, incontinence rates, time to return to work or normal function, resource use in terms of number of dressing changes or visits to a nurse, or change in wound size.

There is no high quality evidence for the use of packing for healing perianal abscess cavities.

Assessed as up to date to 17th May 2016. 
SUMMARY OF FINDINGS FOR THE MAIN COMPARISON [Explanation]

\section{Packing compared with no packing for perianal abscess cavities}

Patient or population: patients aged 18 years or over with primary perianal abscess

Settings: hospital followed by community nursing care

Intervention: packing of perianal abscess cavities

Comparison: no packing of perianal abscess cavities

\begin{tabular}{|c|c|c|c|c|c|}
\hline \multirow[t]{2}{*}{ Outcomes } & \multicolumn{2}{|c|}{ Difference in continuous outcomes } & \multirow{2}{*}{$\begin{array}{l}\text { № of participants } \\
\text { (studies) }\end{array}$} & \multirow{2}{*}{$\begin{array}{l}\text { Quality of the evidence } \\
\text { (GRADE) }\end{array}$} & \multirow[t]{2}{*}{ Comments } \\
\hline & Packing & No packing & & & \\
\hline \multirow[t]{2}{*}{ Time to wound healing } & $\begin{array}{l}\text { Mean time to wound healing } \\
\text { 26.8 days (SD } 7.1 \text { ) }\end{array}$ & $\begin{array}{l}\text { Mean time to wound healing } \\
19.5 \text { days (SD 10.2). Time } \\
\text { to healing with packing took } \\
7.3 \text { days more ( } 2.24 \text { less to } \\
16.84 \text { more) }\end{array}$ & $\begin{array}{l}14 \\
\text { (1 study) }\end{array}$ & $\begin{array}{l}\oplus \oplus \bigcirc \bigcirc^{1} \\
\text { very low }\end{array}$ & $\begin{array}{l}\text { Highly uncertain whether } \\
\text { packing makes a difference } \\
\text { to time to healing }\end{array}$ \\
\hline & $\begin{array}{l}\text { Median time to wound heal- } \\
\text { ing } 24.5 \text { days (range } 10 \text { to } \\
150 \text { ) }\end{array}$ & $\begin{array}{l}\text { Median time to wound heal- } \\
\text { ing } 21.0 \text { days (range } 8 \text { to } 90 \\
\text { days). }\end{array}$ & $\begin{array}{l}43 \\
\text { (1 study) }\end{array}$ & $\begin{array}{l}\oplus \bigcirc \bigcirc \bigcirc^{2} \\
\text { very low }\end{array}$ & $\begin{array}{l}\text { Highly uncertain whether } \\
\text { packing makes a difference } \\
\text { to time to healing }\end{array}$ \\
\hline $\begin{array}{l}\text { Wound pain at initial dress- } \\
\text { ing change } \\
\text { Scale: VAS (high score= } \\
\text { worse pain) } \\
\text { Follow up: dressing change } \\
\text { on day } 1 \text { post-operation }\end{array}$ & \multicolumn{2}{|c|}{$\begin{array}{l}\text { Median wound pain scores post-treatment were reported } \\
\text { in both studies. Data were insufficient to conduct a meta- } \\
\text { analysis. Neither study found a clear difference in median } \\
\text { pain score between groups }\end{array}$} & $\begin{array}{l}57 \\
\text { (2 studies) }\end{array}$ & $\begin{array}{l}\oplus \bigcirc \bigcirc \bigcirc^{3} \\
\text { very low }\end{array}$ & $\begin{array}{l}\text { Highly uncertain whether } \\
\text { packing affects patients'ex- } \\
\text { periences of pain at first } \\
\text { dressing change. }\end{array}$ \\
\hline $\begin{array}{l}\text { Wound pain over } 2 \text { weeks } \\
\text { Scale: VAS (high score= } \\
\text { worse pain) } \\
\text { Follow up: } 2 \text { weeks }\end{array}$ & \multicolumn{2}{|c|}{$\begin{array}{l}\text { Median wound pain score at two weeks follow-up was } \\
\text { reported in both studies. Data were insufficient to conduct } \\
\text { a meta-analysis. Both studies reported more pain with } \\
\text { packing }\end{array}$} & $\begin{array}{l}57 \\
\text { (2 studies) }\end{array}$ & $\begin{array}{l}\oplus \bigcirc \bigcirc \bigcirc^{3} \\
\text { very low }\end{array}$ & $\begin{array}{l}\text { Patients may have experi- } \\
\text { enced more pain with pack- } \\
\text { ing compared with no pack- } \\
\text { ing at } 2 \text { weeks follow-up. } \\
\text { This pain assessment was } \\
\text { retrospective }\end{array}$ \\
\hline
\end{tabular}




\section{GRADE Working Group grades of evidence}

High quality: We are very confident that the true effect lies close to that of the estimate of the effect

Moderate quality: We are moderately confident in the effect estimate: The true effect is likely to be close to the estimate of the effect, but there is a possibility that it is substantially different

Low quality: Our confidence in the effect estimate is limited: The true effect may be substantially different from the estimate of the effect

Very low quality: We have very little confidence in the effect estimate: The true effect is likely to be substantially different from the estimate of effect

Downgraded 3 levels: serious limitation due to lack of blinding; very serious imprecision due to small sample size

2 Downgraded 4 levels: serious limitation due to attrition bias; serious indirectness due to our inability to completely assess

healing data in the absence of measures of variance; very serious imprecision due to small sample size

3 Downgraded 4 levels: serious limitation due to lack of blinding and attrition bias; serious indirectness due to inability to

assess appropriateness of outcome data analysis; very serious imprecision due to small sample size 


\section{B A C K G R O U N D}

\section{Description of the condition}

A perianal abscess is a collection of pus under the skin around the anus. Most perianal abscesses result from an infection in the anal glands (cryptoglandular infection), which can then spread via several different routes. The most common spread of infection is a downward extension to the perianal skin, forming a perianal abscess (Parks 1961). Alternatively, infection may spread alongside the rectum (ischiorectal), upwards above the muscles of the pelvic floor (supralevator), or between the muscles of the anal canal (intersphincteric) (Parks 1976). Extension across the midline of the body results in a horseshoe abscess. The cause of cryptoglandular infection is unique to perianal abscesses, and therefore, makes this condition pathologically distinct from abscesses in other locations. Approximately $10 \%$ of perianal abscesses are not caused by infected anal glands and result from conditions such as: skin appendage infection; Crohn's disease; tuberculosis; trauma; chronic inflammation and infection of sweat glands (hidradenitis suppurativa); human immunodeficiency virus (HIV) infection; sexually transmitted diseases; radiation therapy; malignancy or foreign bodies (Eisenhammer 1978; Goligher 1984; Hamadani 2009; Nelson 1985; Phillips 1997; Sangwan 1996; Whiteford 2007). In the UK, the annual incidence of perianal abscess is estimated to be 40 per 100,000 of the adult population, and acute perianal abscess is the seventh most common emergency condition in general surgery (www.hesonline.gov.uk). During 2013 to 2014, perianal abscesses resulted in 18,079 hospital episodes in England (diagnosis codes: anal abscess, anorectal abscess, ischiorectal abscess, intersphincteric abscess) (www.hesonline.gov.uk). This represents 3\% $(18,079$ out of 634,971$)$ of all general surgery emergency hospital episodes, and equates to $1 \%(18,079$ out of $1,867,469)$ of total general surgery hospital episodes. The acute and ongoing management of perianal abscess cavities accounts for significant hospital and community resource utilisation in England, and probably elsewhere, although we have been unable to locate equivalent nonUK data to support this.

Depending on the exact anatomical location, perianal abscesses usually result in pain, swelling, and redness of the anal area. Other symptoms may include fever and malaise. Over time, abscesses increase in size and, if untreated, will usually burst, which may or may not result in adequate drainage of the pus. It is thought that if the pus is not adequately drained, the skin may close prematurely and the abscess could recur. More rarely, untreated abscesses can also result in severe whole body (systemic) infection or devastating, rapidly spreading tissue infection and gangrene (necrotising fasciitis), therefore, early surgical drainage of the abscess is recommended.

In the UK, standard surgical drainage involves incising the skin over the abscess in order to drain all the pus and allow wound irrigation. Following drainage, an internal dressing is applied ('packed') to the resulting cavity for haemostasis; that is control of bleeding from the small blood vessels that line the abscess cavity. Common practice in the UK is to continue packing until the abscess cavity has healed (by secondary intention). The pack is changed every day or every few days by community nursing teams.

Alternative strategies for managing the abscess cavity have been tried. In the USA and Australia, one variation in the technique for incision and drainage is to use a small stab incision and place a latex catheter (e.g. a 10-14F de Pezzer catheter) into the cavity (Beck 1988; Isbister 1987; Kyle 1990). This is done under local anaesthetic, unlike practice in the UK, where a general anaesthetic is routinely used. The catheter is cut short and drains into an external dressing. It is removed when it stops draining. In the USA, simple drainage is often performed in an outpatient setting under local anaesthetic (Whiteford 2007).

Sewing up (following incision, drainage and curettage) of the abscess cavity with primary sutured closure was first described in 1960 (Ellis 1960). Primary closure with antibiotic treatment may result in reduced healing times, but the increased incidence of recurrent sepsis negates any benefit (Mortensen 1995). This technique of primary closure is no longer used.

Sitz baths (immersing the area in warm water) have been used for treating perianal abscess cavities following incision and drainage. These have been employed both with packing (Read 1979), and without packing (Tang 1996; Vasilevsky 1984). Although a review of the literature found no benefit for this practice, it makes sense to irrigate an infected wound (Tejirian 2005).

Perianal fistulae (fistulae-in-ano) are a complication of perianal abscesses. A fistula may occur if a perianal abscess drains spontaneously through the perianal skin, and if the infection becomes chronic (Parks 1961). The fistula becomes a tract between the anal canal and the perianal skin that is lined with granulation tissue (present in healing wounds) or skin cells (epithelium). It intermittently discharges pus and may result in recurrent abscesses. Fistulae usually require surgical intervention. This can be at the time of initial abscess drainage (Malik 2010), but usually is performed later. Up to a third of patients with a perianal abscess will develop a fistula (Hamadani 2009; Lohsiriwat 2010; Ramanujam 1984; Vasilevsky 1984).

Following incision and drainage, management of the remaining wound cavity becomes the primary clinical focus to ensure optimal wound closure and prevent recurrence. In the UK, anecdotally, it is common for the cavity to be dressed with an internal dressing (packed) and covered with an external dressing or pad. However, in some other countries, e.g. Germany, use of an internal dressing (packing) is not routinely recommended (Ommer 2012). This review focuses on the impact of internal dressings (packing) on the healing of cavities resulting from the surgical drainage of perianal abscesses.

\section{Description of the intervention}


Several dressing types are available to manage perianal abscess cavities; we have summarised the key categories below. There are limited audit type data available on the types of dressings that are used for packing cavities resulting from the drainage of perianal abscesses. Where packing is not used, the wound may just be covered with an external dressing that is not in contact with the cavity itself.

\section{Basic wound contact dressings}

Low-adherence dressings and wound contact materials: usually cotton pads that are placed directly in contact with the wound. These can be non-medicated (e.g. paraffin gauze dressing) or medicated (e.g. containing povidone iodine or chlorhexidine).

Absorbent dressings: applied directly to the wound or used as secondary absorbent layers in the management of heavily exuding wounds.

\section{Advanced wound dressings}

Alginate dressings: highly absorbent dressings made of calcium alginate, or calcium sodium alginate, that may be combined with collagen. The alginate forms a gel when in contact with moisture; this gel can be lifted off when the dressing is removed or rinsed away with sterile saline. Bonding the alginate to a secondary viscose pad increases absorbency.

Foam dressings: normally these contain hydrophilic polyurethane foam and are designed to absorb wound exudate and maintain a moist wound environment. There are various versions, and some include additional absorbent materials, such as viscose and acrylate fibres or particles of superabsorbent polyacrylate, which are silicone-coated for non-traumatic removal.

Hydrocolloid dressings: these are occlusive dressings usually composed of a hydrocolloid matrix bonded onto a vapour-permeable film or foam backing. When in contact with the moisture at the wound surface this matrix forms a gel to provide a moist environment. Fibrous alternatives have been developed that resemble alginates and are not occlusive, but which are more absorbant than standard hydrocolloid dressings.

Capillary action dressings: these consist of an absorbent core of hydrophilic fibres held between two low-adherent contact layers. Odour absorbent dressings: these dressings contain charcoal and are used to absorb wound odour. Often these types of wound dressings are used in conjunction with a secondary dressing to improve absorbency.

\section{How the intervention might work}

It is thought that use of an internal dressing (packing) initially aids haemostasis. Continued packing over days to weeks is thought to promote healing by secondary intention, by preventing the wound edges from closing prematurely. It is thought that healing in this way prevents the recurrence of the abscess.

\section{Why it is important to do this review}

It is unclear whether packing (compared with not packing) of the cavity following drainage of a perianal abscess is advantageous in promoting healing and preventing adverse events, including fistula formation, abscess recurrence, and wound pain. Anedoctally, the use of packing as a treatment approach in this context varies internationally, and there is limited guidance for practice (Ommer 2012; Steele 2011; Williams 2007). A German guideline that reported on the diagnosis and treatment of anal abscess stated that regular packing is not required (Ommer 2012), and cited one small trial to support this (Tonkin 2004).

Packing has implications for patients and healthcare services: regular changing of internal dressings (change of packing) requires a considerable amount of community nursing time and is, anecdotally, painful for patients. Additionally, the associated healthcare appointments may require patients to take time off work. We believed a transparent and robust review is required to investigate the benefits, harms, and costs of packing (compared with not packing) post-operative perianal abscess cavities, in order to identify, synthesise and report the current evidence base.

\section{O B J E C T I VES}

To assess the effects of internal dressings in healing wound cavities after drainage of perianal abscesses.

\section{METHODS}

\section{Criteria for considering studies for this review}

\section{Types of studies}

We planned to include published and unpublished randomised controlled trials (RCTs; i.e. must be described as randomised in the report), reported in any language, conducted in any country or setting. RCTs reported as conference abstracts would have only been included where there was sufficient information available for data extraction and risk of bias assessment (either from the abstract or from the trial authors). RCTs that used a cross-over design would have been included provided that outcome data were available at the point of cross-over. We would have also included RCTs with cluster randomisation. We would have excluded quasirandomised studies.

\section{Types of participants}

Trials recruiting people undergoing surgical drainage of a perianal abscess. We have included studies involving participants of any age, with any underlying aetiological cause for abscess formation. 


\section{Types of interventions}

Any type of internal dressing (packing) used in the post-operative management of perianal abscess cavities. We have included studies where the presence or absence of an internal dressing (or packing) was the only systematic difference between treatment groups. Comparisons could have included internal dressings compared with no internal dressing; one type of internal dressing compared with another type of internal dressing; or internal dressings compared with non-dressing treatments (for example, topical applications, drainage with a drain rather than an incision).

\section{Types of outcome measures}

We have included studies that report one or more of the outcomes below.

Primary outcomes

\section{Wound healing}

The primary effectiveness outcome for this review was wound healing. Trialists used a range of different methods of measuring and reporting this outcome. We considered RCTs that reported one or more of the following to provide the most relevant and rigorous measures of wound healing.

- Time to complete wound healing (correctly analysed using survival, time-to-event approaches). Ideally the outcome will have been adjusted (by study authors) for appropriate covariates e.g. baseline ulcer area/duration.

- Proportion of wounds completely healed during follow-up (frequency of complete healing).

We used, and reported, study authors' definitions of wound healing. We reported outcome measures at the latest time point available (assumed to be length of follow-up, if not specified) and the time point specified in the methods as being of primary interest (if this was different from the latest time point available).

Where both the outcomes above were reported, we planned to present all data for reference, but to focus on reporting time to healing. When time was analysed as a continuous measure, but it was unclear whether all wounds healed, we documented the use of the outcome in the study, but did not extract, summarise or use the data in a meta-analysis.

\section{Wound pain}

- Changes or comparison of validated pain scores, including pain measured on a visual analogue scale (VAS), during treatment or at dressing change, or both.

\section{Secondary outcomes}

- Participant health-related quality of life/health status (measured using a standardised generic questionnaire such as EQ-5D, SF-36, SF-12, or SF-6, at noted time points). We have not included ad hoc measures of quality of life that are likely not to be validated and will not be common to multiple trials.

- Frequency of abscess recurrence and fistulae.

- Faecal Incontinence.

- Time to return to work/normal function after perianal abscess incision and drainage.

- Resource use (including measurements of resource use such as number of dressing changes, nurse visits, length of hospital stay and re-operation/intervention).

- Change (and rate of change) in wound size, with adjustment for baseline size (we attempted to contact study authors to request adjusted means when not presented). When change or rate of change in wound size was reported without adjustment for baseline size, we planned to document use of the outcome in the study, but not to extract data, summarise it or use it in any meta-analysis.

\section{Search methods for identification of studies}

\section{Electronic searches}

In May 2016, we searched the following databases to identify reports of relevant clinical trials:

- The Cochrane Wounds Specialised Register (searched 17th May 2016);

- The Cochrane Central Register of Controlled Trials

(CENTRAL) (The Cochrane Library) (2016, Issue 4);

- Ovid MEDLINE (1946 to 17 May 2016);

- Ovid MEDLINE (In-Process \& Other Non-Indexed Citations) (searched 17 May 2016);

- Ovid EMBASE (1974 to 17 May 2016);

- EBSCO CINAHL Plus (1937 to 17 May 2016).

The search strategies for CENTRAL, Ovid MEDLINE, Ovid EMBASE and EBSCO CINAHL Plus can be found in Appendix 1. We combined the Ovid MEDLINE search with the Cochrane Highly Sensitive Search Strategy for identifying randomised trials in MEDLINE: sensitivity- and precision-maximising version (2008 revision) (Lefebvre 2011). We combined the EMBASE search with the Ovid EMBASE randomised trials filter terms developed by the UK Cochrane Centre (Lefebvre 2011). We combined the CINAHL search with the randomised trials filter terms developed by the Scottish Intercollegiate Guidelines Network (SIGN 2015). We did not restrict studies with respect to language, date of publication, or study setting.

We also searched the following clinical trials registries:

- ClinicalTrials.gov (http://www.clinicaltrials.gov/). 
- The World Health Organization (WHO) International Clinical Trials Registry Platform (ICTRP) (http://apps.who.int/ trialsearch/Default.aspx).

- The European Union (EU) Clinical Trials Register (https:// www.clinicaltrialsregister.eu/).

- Japan Registries Network (JPRN) (http://umin.ac.jp).

- Australia and New Zealand Clinical Trials Registry (ANZCTR) (http://www.anzctr.org.au).

\section{Searching other resources}

We were keen to explore sources of unpublished data. To maximise identification of unpublished studies, not located during the search stage, we searched the bibliographies of all retrieved and relevant publications identified by these search strategies for further studies. We also examined the content of conference proceedings and systematic reviews in the field that may refer to data we have not found. We contacted key manufacturers (MöInlycke Health Care Ltd, 3M, ConvaTec UK, Aspen Medical Europe Ltd, Syngery Health Plc, Covidien (now Medronic Minimally Invasive Therapies), and Smith and Nephew Plc) to ask about unpublished (as well as ongoing) work.

We identified key authors and opinion leaders in the field as those from large research units, editors of colorectal journals, and individuals who had previously published on related subjects and contacted them.

We also searched for key abstracts from the following meetings, and requested unpublished data from the authors as required:

- The American Society of Colon and Rectal Surgeons

- Association of Coloproctology of Great Britain and Ireland (ACPGBI)

- Section of Coloproctology, Royal Society of Medicine

- Section of Colon and Rectal Surgery, Royal Australasian College of Surgeons

- Colorectal Surgical Society of Australia and New Zealand

- European Society of Coloproctology (ESCP)

- Tripartite meeting (a combined meeting of the above Associations).

Finally, we performed a Google Scholar search (18 May 2016).

\section{Data collection and analysis}

\section{Selection of studies}

Independently, two review authors (JS and $\mathrm{KN}$ ) assessed the titles and abstracts of retrieved studies for relevance. After this initial assessment, we obtained full copies of all studies felt to be potentially relevant. Independently, two review authors (KN and JS) checked the full papers for eligibility; disagreements were resolved by discussion and, where required, the input of a third review author (SS). We recorded all reasons for exclusion of studies for which we obtained full copies. A completed PRISMA flowchart summarises this process (Figure 1; Liberati 2009). 
Figure I. Study flow diagram.

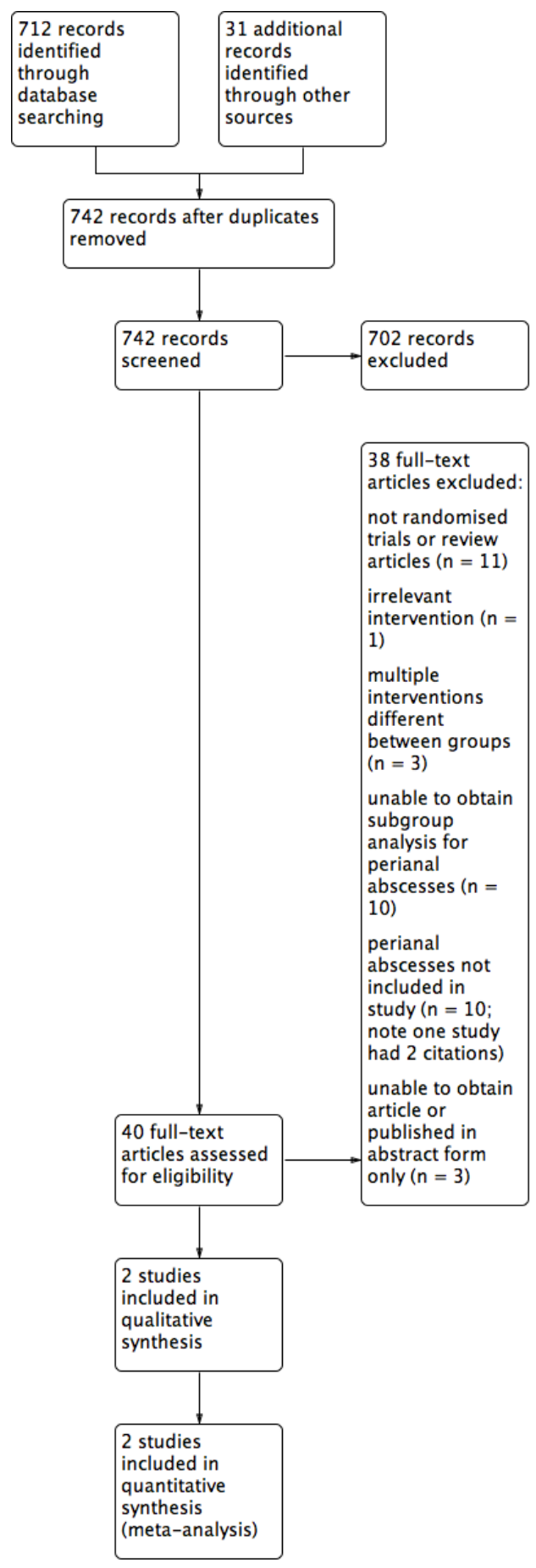

Internal dressings for healing perianal abscess cavities (Review)

Copyright $\odot 2016$ The Cochrane Collaboration. Published by John Wiley \& Sons, Ltd. 


\section{Data extraction and management}

We extracted and summarised details of the eligible studies using a data extraction sheet. Two review authors (KN and SS) extracted data independently and resolved disagreements by discussion. Where data were missing from reports, we attempted to contact the study authors to obtain this information. We included studies published in duplicate only once, but extracted the maximal amount of data. Where possible, we extracted date relating to:

- country of origin;

- participants' type and location of abscess - where recorded;

- unit of randomisation and analysis;

- care setting;

- number of participants randomised to each trial arm;

- eligibility criteria and key baseline participant data;

- details of the intervention regimen received by each group;

- details of any co-interventions;

- primary and secondary outcome(s) (with definitions);

- outcome data for primary and secondary outcomes (by group);

- duration of follow-up;

- number of withdrawals (by group);

- adverse events;

- publication status of study; and,

- sources of funding for the trial.

\section{Assessment of risk of bias in included studies}

Two review authors (KN and SS) independently assessed each included study for bias using the Cochrane tool for assessing risk of bias (Higgins 2011a). This tool addresses six specific domains, namely sequence generation, allocation concealment, blinding, incomplete outcome data, selective outcome reporting, and other issues (e.g. issues with unit of investigation). Please see Appendix 2 for details of the criteria upon which judgements were made. We assessed blinding and completeness of outcome data for each outcome separately. We completed a 'Risk of bias' table for the eligible study. We presented the assessment of risk of bias using a 'Risk of bias' summary figure, which presents all of the judgements in a cross-tabulation of study by entry. This display of internal validity indicates the weight the reader has given the results of each study. We resolved disagreements about risk of bias assessment by discussion. Where possible, when a lack of reported information resulted in a decision of 'unclear', we contacted trial authors for clarification.

We classified trials as being at high risk of bias overall if they were rated 'high risk' for any one of three key criteria, namely: randomisation sequence, allocation concealment, and blinded out- come assessment. We note it was unlikely that studies assessed at high risk of bias for the generation of randomisation sequence would be included in the review as they would likely not fulfil the criteria of being a RCT. If insufficient detail relating to the conduct of the study was reported, then we classified the study as 'unclear risk' of bias. We classified studies as 'low risk' of bias when sufficient information relating to randomisation sequence, allocation concealment, and blinding was provided and we judged the methodology to be at low risk of bias. We also considered the potential for performance and measurement bias for each primary and secondary outcome we extracted.

\section{Measures of treatment effect}

Where possible, we presented the outcome results for each trial with $95 \%$ confidence intervals (CI). We reported estimates for dichotomous outcomes (e.g. healed: yes/no) as risk ratios (RRs). We used the RR rather than odds ratio (OR), since, when event rates are high, as is the case for many trials reporting wound healing, ORs (when interpreted as RRs) can give an inflated impression of the effect size (Deeks 2002). We reported outcomes relating to continuous data (e.g. pain) as mean differences (MDs) and overall effect size (with $95 \% \mathrm{CI}$ ). Where treatment outcomes are measured in different ways, we calculated the standardised mean, correcting for direction of scale as appropriate. Where a study reported time to healing data (the probability of healing over a consecutive time period), we planned to report and plot this data (where possible) using hazard ratio estimates.

\section{Unit of analysis issues}

We anticipated that most participants would only have one abscess being operated on. For abscess healing, unless otherwise stated, where the number of abscesses appeared to equal the number of participants, we treated the participant as the unit of analysis. However, on occasions where multiple abscesses on a participant had been assessed, we planned to record whether this had been accounted for in the analyses. Where data from cluster-randomised trials are included in the review we planned to adjust for cluster (as the unit of analysis) using a design effect (where possible) (Higgins 2011b). For adverse event outcomes, in order to facilitate further analyses, we planned to establish whether data were presented at the level of the participant, because there is potential for data to refer to multiple events occurring to a single abscess (person), which means that the data cannot be analysed further without violating the assumption of independence.

\section{Dealing with missing data}


The problem of missing data is common in trial reports. Excluding participants from the analysis post-randomisation or ignoring those participants lost to follow-up can, in effect, compromise the process of randomisation, and thus, potentially introduce bias into the trial. In individual studies, where data on the proportion of wounds healed were presented, we assumed that, if randomised participants were not included in an analysis, their wounds did not heal (i.e. they were considered in the denominator but not the numerator). Where a trial did not specify participant group numbers prior to dropout, we planned to present only complete case data. In a time-to-healing analysis using survival analysis methods, dropouts should be accounted for as censored data. Hence, all participants should contribute to the analysis. We planned to present data for area change, and for all secondary outcomes, as a complete case analysis. Where there was no measure of variance for a continuous outcome, and no response from the authors, we planned to impute standard deviations/standard errors where possible. If such calculations were not possible, we anticipated that we would be unable to analyse or pool the relevant data.

\section{Assessment of heterogeneity}

We considered both clinical and statistical heterogeneity. Wherever appropriate, that is where studies appeared similar in terms of abscess type, intervention type, duration, and outcome type, we pooled data using meta-analysis, conducted using Review Manager 5 (RevMan 2014). As well as exploring clinical and methodological heterogeneity, we assessed statistical heterogeneity using the $\mathrm{Chi}^{2}$ test (we considered a significance level of P less than 0.1 to indicate statistically significant heterogeneity) and the $\mathrm{I}^{2}$ estimate (Higgins 2003). The $I^{2}$ estimate examines the percentage of total variation across studies due to heterogeneity, rather than to chance. Values of $\mathrm{I}^{2}$ over $50 \%$ indicate a moderate level of heterogeneity, and values over $75 \%$ indicate a high level of heterogeneity (Higgins 2003).

\section{Data synthesis}

We combined studies using a narrative overview and conducted meta-analyses of outcome data where appropriate (in Review Manager 5; RevMan 2014). The decision to include studies in a metaanalysis depended on the availability of treatment effect data and assessment of heterogeneity. If it was decided to undertake metaanalysis in the presence of clinical heterogeneity (review author judgement) or evidence of statistical heterogeneity, or both, we planned to use the random-effects model. We planned to use a fixed-effect approach only when clinical heterogeneity was thought to be minimal and statistical heterogeneity was estimated as nonstatistically significant for the $\mathrm{Chi}^{2}$ value and $0 \%$ for the $\mathrm{I}^{2}$ assessment (Kontopantelis 2013). For time-to-event data, we planned to use the inverse variance method on the estimated hazard ratio and standard error, when reported (or calculated from reported data if possible).

\section{'Summary of findings' table}

We presented the main results of the review in a 'Summary of findings' table. These tables present key information concerning the quality of the evidence, the magnitude of the effects of the interventions examined, and the sum of available data for the main outcomes (Schunemann 2011a). The 'Summary of findings' table also includes an overall grading of the evidence related to each of the main outcomes using the Grades of Recommendation, Assessment, Development and Evaluation (GRADE) approach. The GRADE approach defines the quality of a body of evidence as the extent to which one can be confident that an estimate of effect, or association, is close to the true quantity of specific interest. The quality of a body of evidence involves consideration of withintrial risk of bias (methodological quality), directness of evidence, heterogeneity, precision of effect estimates, and risk of publication bias (Schunemann 2011b). We presented the following outcomes in the 'Summary of findings' table.

- Time to wound healing

- Wound pain.

Where data were not pooled, we presented a GRADE assessment without a 'Summary of findings' table.

\section{Subgroup analysis and investigation of heterogeneity}

If data had been available, potential subgroup analyses planned were:

- underlying aetiological cause, e.g. cryptoglandular disease, Crohn's disease, immunosuppression, trauma, sexually transmitted infection;

- anatomical classification of abscess, e.g. horseshoe abscess (where abscess originates on one side of the perianal region and crosses the midline); and

- participant population age, e.g. under 18 years of age and over 18 years of age.

\section{Sensitivity analysis}

If possible, we planned to undertake a sensitivity analysis to investigate the effects of removing studies classed as being at high risk of selection, performance, detection, or attrition bias from the analysis.

\section{R E S U L T S}

\section{Description of studies}

\section{Results of the search}

See Figure 1 for a summary of results of our search. 
The search returned 742 citations. After screening, we attempted to retrieve 40 full-texts pertaining to 36 studies potentially relevant to the review (three articles were review articles: Fitch 2007, Milne 2010, and Barnes 1988; and one study had two citations: Cooper 1995). Of these, we excluded 34 studies and included two studies. We also contacted six opinion leaders who had no studies to add to those identified. We contacted seven dressing manufacturers. Only two responded, and they had no studies to add to those identified.

A search of trials registries resulted in 10 potential additional studies, of which we excluded three at the screening stage, based upon available information. We obtained further details from study investigators in two cases, and excluded these studies as they do not include perianal abscesses (Myers 2015), or the comparator intervention being investigated was not a dressing (Gustafsson 2015). Three studies were published, of which we excluded two from the review (Edino 2001; Singer 2013) and included one (Perera 2015). Two studies are ongoing and we have recorded these as awaiting assessment (NCT02286479; NCT01897675).

\section{Included studies}

See Characteristics of included studies tables for a summary of the included studies.

This review included two studies, both were conducted in single centres, one in Australia (Tonkin 2004), and one in the UK (Perera 2015). Both studies included participants aged 18 years or over with an anorectal (perianal) abscess. Both studies excluded participants with abscesses secondary to another cause, such as Crohn's disease, those requiring a second operation for undrained sepsis, and those unable to give consent. Perera 2015 also excluded participants who had a fistula detected at operation, unlike Tonkin 2004 who treated the fistula at operation and included the participants in the study.

The included studies were both small (Perera 2015: $\mathrm{n}=14$; and Tonkin 2004: $\mathrm{n}=50$ ) with similar study designs randomising participants to packing or non-packing of their perianal abscess. Tonkin 2004 gave some details as to the surgical technique: all participants had their abscess incised and drained using an elliptical incision to "deroof" the cavity and a pack was inserted for haemostasis. Perera 2015 only describes incision and drainage under general anaesthesia with insertion of a haemostatic pack. In both studies, participants were enrolled to the study on the first post-operative day and randomised to continued packing by community district nursing teams or no packing. Participants in the non-packing group managed their own wounds in the community. In Tonkin 2004, absorbant dressings were used to cover the area. In both studies, fortnightly follow-up was undertaken until the cavity was closed and the skin re-epithelialised, which constituted healing. In Perera 2015, the minimum follow-up was six months to establish whether abscess recurrence had occurred. In both studies, telephone follow-up was conducted for non-attenders.

Outcomes of interest reported in both studies were wound healing, wound pain, fistula formation, and abscess recurrence.

\section{Excluded studies}

See Characteristics of excluded studies tables for a summary of the excluded studies.

Of the 40 full-text articles we retrieved, three were review articles and one study had two citations. Of the 36 studies remaining, we excluded 34 studies at the full-text stage, including two studies for which full-text articles were not available (Edino 2001; Meng 2005)

One study was only published in abstract form and the authors were not contactable (Gibson 1994).

Eight studies were non-randomised (Beck 1988; Gajiwala 2006; Guest 2005; Isbister 1987; Kyle 1990; Lundhus 1993; Ritchie 1972; Wilson 1964).

One study had an irrelevant intervention (Llera 1985).

Three studies included packing versus a group with multiple different interventions, making analysis of the lack of packing impossible (Kronborg 1984; Leaper 1976; Sørensen 1987).

Ten studies included abscesses on multiple sites of the body, and it was not possible to get subgroup analyses for the participants with perianal abscesses (Abraham 1997; Alimov 2013; Dawson 1992; Gupta 1992; Macfie 1977; Moore 2000; Simms 1982; Stewart 1985; Williams 1995; Wu 2008).

Nine studies included abscesses on multiple sites of the body, but did not include perianal abscesses (Berry 1993; Butterworth 1991; Cooper 1995; Kessler 2012; Koehler 2009; O’Malley 2009; Singer 2013; Ubbink 2008; Young 1982).

\section{Risk of bias in included studies}

See Characteristics of included studies for risk of bias data for the included study, and Figure 2 for the risk of bias summary, for the included studies. 
Figure 2. Risk of bias summary: review authors' judgements about each risk of bias item for the included study.

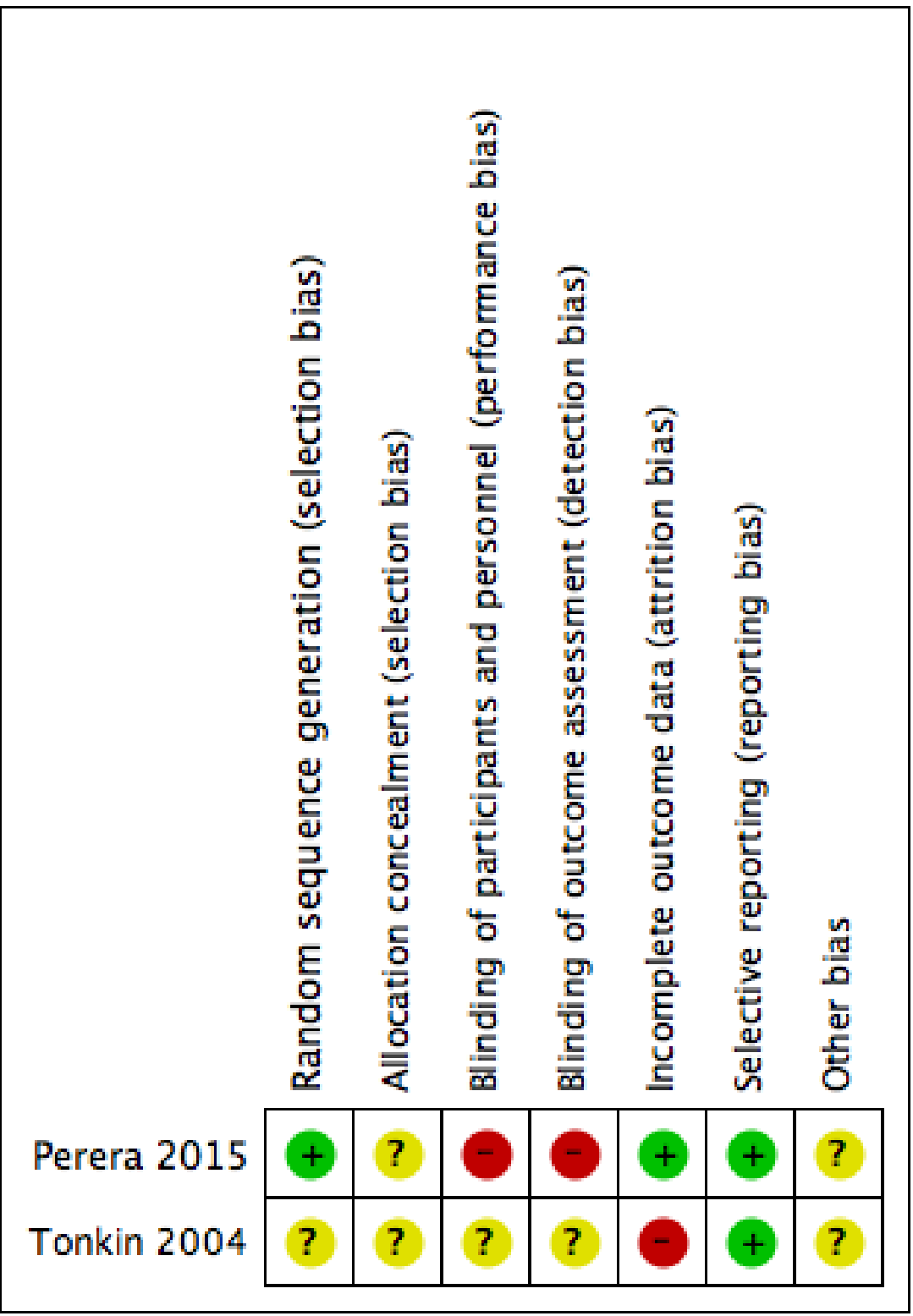




\section{Allocation}

Tonkin 2004 gave no information as to how the randomisation sequence was generated. Allocation was undertaken using sealed envelopes but it was not clear whether these were numbered. Consquently, we classed the study as being at unclear risk of selection bias. Perera 2015 utilised a computer-generated randomisation sequence which is considered at low risk of bias, but, again, the allocation was conducted using sealed envelopes and it was not clear whether these were numbered. We therefore, classed this study as being at unclear risk of selection bias.

\section{Blinding}

There is no record of the use of blinding in either study. Tonkin 2004 recruited post-operatively, so there is unlikely to be risk of bias in the operative technique. Tonkin 2004 does not comment on the use of blinding, and this may have resulted in detection bias. We deemed this study as having an unclear risk of detection bias.

Perera 2015 recruited the majority of participants post-operatively and it is unclear if this has had an impact on bias. Perera 2015 did not blind participants or investigators due to the nature of the intervention, which could result in detection bias. We deemed this study at high risk of detection and performance bias.

\section{Incomplete outcome data}

Tonkin 2004 lost seven participants to follow-up (three in the packing group and four in the non-packing group). This represents $14 \%$ of the study population. It was considered to have substantial impact on the results and was deemed to be at high risk of attrition bias.

Perera 2015 did not lose any participants to follow-up. No participants withdrew and no intervention was discontinued. All follow-up conducted in person and no adverse events occurred. We considered the study to be at low risk of attrition bias.

\section{Selective reporting}

Both studies reported all outcomes recorded in the trial methods, but the protocols were not scrutinised. We deemed the studies to be at low risk of reporting bias.

\section{Other potential sources of bias}

Tonkin 2004 followed participants up fortnightly until healed. However, one participant is described as taking more than 12 months to heal, and appears to have been omitted from the analysis. The effect of this bias is unclear.

\section{Effects of interventions}

See: Summary of findings for the main comparison Summary of Findings Table

Comparison 1: Packing compared with no packing in patients with perianal abscesses ( 2 trials; 64 participants)

Primary outcome: Time to complete wound healing

Tonkin 2004 reports a median time to healing of 24.5 days (range 10 to 150 days) in the packing group and 21.0 days (range 8 to 90 days) in the non-packing group. The study authors report that the difference was not statistically significant $(P=0.214)$ but their methods note that the Mann-Whitney $U$ test has been used for the analysis. This does not take censoring into account and is not the most appropriate statistical method to use. Based on available data we have not been able to re-analyse the study.

GRADE assessment: Very low quality evidence; downgraded one level for serious limitation (attrition bias), serious indirectness we were unable to assess the time to healing data fully, given data and analyses presented. We also downgraded two levels for very serious imprecision as this was a small study $(n=50)$, but since 95\% confidence intervals (CIs) around the treatment effect were not presented, the impact of this could not fully be assessed. Risk of bias for this study was unclear due to poor reporting.

Perera 2015 reported a mean time to healing of 26.8 days $(95 \%$ CI 22.7 to 30.7$)$ in the packing group and 19.5 days (95\% CI 13.6 to 25.4 ) in the non-packed group (it was not clear whether all participants healed). A log rank test was used for the analysis and the time to healing was reported to be reduced in the nonpacking group compared to the packing group $(\mathrm{P}=0.047)$. We re-analysed the data and found no clear difference in the time to healing (7.30 days, $95 \%$ CI -2.24 to 16.84 ; participants $=14$ ) Analysis 1.1.

GRADE assessment: Very low quality evidence; downgraded two levels for imprecision as this was a very small study $(\mathrm{n}=14)$, and one level for limitations in the design as there is a lack of blinding, which is likely to result in performance and detection bias.

We have not assessed the proportion of wounds completely healed during follow-up as this was not reported in either study.

Primary outcome: Wound pain

Both studies recorded pain scores with a $10 \mathrm{~cm}$ visual analogue scale (VAS). Traditionally, the VAS has word descriptors at each end, for instance "no pain" and "very severe pain." The participant marks on the line where they think their pain is between those two points. This mark is then measured from the "no pain" descriptor. It is standard that the higher the score, the worse the pain. Although neither study has confirmed that they used the VAS in this way, we have assumed that they have adopted the standard reporting technique.

Tonkin 2004 reported median VAS pain scores as 8 in the packing 
group compared to 4.5 in the non-packing group at the initial dressing change following randomisation $(P=0.296)$. Perera 2015 reported median VAS pain scores as 3 (interquartile range (IQR) = 6) in the packing group compared to $2(\mathrm{IQR}=4.5)$ in the nonpacking group at the initial dressing change following randomisation $(P=0.648)$. In both studies, the authors report that this difference was not statistically significant. We have not been able to reproduce these analyses, since variation data, such as the standard error or the standard deviation, were not presented.

At two weeks, both studies asked participants for a retrospective judgement of pain recorded on a VAS for the overall pain in that time period. However, it is not clear if this time period was two weeks following randomisation or surgery. Tonkin 2004 reported a median VAS score of 2 for the packing group and 0 for the nonpacking group. This was reported by the study authors as being statistically significant $(P=0.004)$ but again no further details are presented and data are not presented in a way that we are able to conduct our own analysis of the aggregate data. Perera 2015 reported a statistically significant $(P=0.030)$ median VAS score of less pain in the non-packing group $(0, \mathrm{IQR}=1)$ compared to the packing group $(2, \mathrm{IQR}=3)$.

GRADE assessment: Very low quality evidence; downgraded one level for indirectness - we were unable to re-create analyses, given the data and analyses presented. We also downgraded two levels for imprecision as this was a small study, but since 95\% CIs around the treatment effect were not presented the impact of this could not fully be assessed and once for limitations in the design due to attrition bias and lack of blinding, which is likely to result in performance and detection bias.

\section{Secondary outcome: Fistula formation}

There was no clear evidence of a difference in the number of postoperative fistulae that formed between the study groups in either study.

Tonkin 2004 reported 4/20 (20.0\%) in the packing group compared with $2 / 23(8.7 \%)$ in the non-packing group during the variable follow-up period (participants were followed up until they were healed): risk ratio (RR) $2.30,95 \%$ CIs 0.47 to 11.26 (Analysis 1.2). The estimate is very imprecise with CIs ranging from a reduction in risk of $53 \%$ to an increase risk of $1126 \%$.

Perera 2015 reported $1 / 8(12.5 \%)$ post-operative fistulae in the packing group compared with $0 / 6(0 \%)$ in the non-packing group during the variable follow-up period (participants were followed up until they were healed or for six months at a minimum): RR 2.33, 95\% CIs 0.11 to 48.99 (Analysis 1.2 ). The estimate is extremely imprecise with CIs ranging from a reduction in risk of $89 \%$ to an increase in risk of $4899 \%$.

Given the clinical and methodological similarities, we pooled the data and the $\mathrm{I}^{2}$ metric returned was $0 \%$ (Analysis 1.2). There was no clear evidence of a difference in post-operative fistulae between groups: RR 2.31, 95\% CIs 0.56 to 9.45 . However, even pooling the data, the sample size remained very small and the estimate was very imprecise.
Grade assessment: Very low quality evidence. Downgraded three levels for very serious imprecision as these were small studies and serious limitations in the design due to attrition bias and lack of blinding, which is likely to result in performance and detection bias.

\section{Secondary outcome: Recurrence of abscess}

There was no clear evidence of a difference in the number of abscess recurrences between the study groups over the variable followup period in either study. Tonkin 2004 reported 1/20 (5.0\%) in the packing group compared with $3 / 23(13.0 \%)$ in the nonpacking group: RR 0.38, 95\% CIs 0.04 to 3.40 (Analysis 1.3). This estimate is very imprecise with CIs ranging from a reduction in risk of abscess recurrence in the packing group of $96 \%$ to an increased risk of $340 \%$.

Perera 2015 reported 3/8 (37.5\%) abscess recurrences in the packing group compared with $2 / 6(33.3 \%)$ in the non-packing group: RR 1.13, 95\% CIs 0.27 to 4.76 (Analysis 1.3). This estimate is very imprecise with CIs ranging from a reduction in risk of $73 \%$ of abscess recurrence in the packing group to an increased risk of $476 \%$.

Given the clinical and methodological similarities, we pooled the data and the $\mathrm{I}^{2}$ metric returned was $0 \%$ (Analysis 1.3). There was no clear evidence of a difference in abscess recurrence groups: RR $0.72,95 \%$ CI 0.22 to 2.37 . However, even pooling the data, the sample size remained very small and the estimate was very imprecise.

Grade assessment: Very low quality evidence. Downgraded three levels for very serious imprecision as these were small studies and serious limitations in the design due to attrition bias and lack of blinding, which is likely to result in performance and detection bias.

\section{Secondary outcome: resource use (hospital stay)}

Tonkin 2004 described the length of hospital stay as "one" in each group. We assume this to mean one day as no units are given for this. The authors report a P value of 0.479 for a Mann-Whitney U statistical comparison between the study groups, but not enough data has been presented for us to synthesise an analysis. There is no clear evidence of a difference between the study groups.

Perera 2015 discharged all participants on day 1 post-operatively. Other secondary outcomes

Unfortunately, we did not find any randomised controlled trials (RCTs) that compared participant health-related quality of life/ health status, incontinence rates, time to return to work or normal function, resource use in terms of number of dressing changes or visits to a nurse, or change in wound size.

\section{DISCUSSION}

\section{Summary of main results}


Data from two studies $(n=64)$ compared packing (standard care with internal dressing) with no packing (no internal dressing) for the treatment of perianal abscess cavities.

Due to the variation in reporting of the time to complete wound healing outcome we were unable to pool data and it was difficult to draw conclusions about the impact of packing on time to complete wound healing. In Tonkin 2004, data were not analysed or presented in a way where variation around the estimates could be assessed. Perera 2015 reported that there was a reduction in time to healing in the non-packing group when the log rank test was applied, but on further analysis of the data we regarded this difference as not statistically significant.

Study authors reported pain data in ways which meant we could not use or re-analyse it. We cannot therefore draw any conclusions regarding the difference in the amount and duration of pain experienced between packing and no packing, although it would be very surprising if there were no difference.

It is unclear whether packing influences the number of post-operative fistulae, abscess recurrences or length of hospital stay.

\section{Overall completeness and applicability of evidence}

The use of internal dressings (packing) compared with no packing for healing perianal abscesses has only been evaluated in two very small randomised controlled trials (RCTs). This results in very limited evidence.

\section{Quality of the evidence}

Overall, the evidence was of very low quality with generally unclear or imprecise estimates. The studies were very small and Tonkin 2004 appeared to remove participants from the analysis.

Both studies were underpowered to detect differences in the number of post-operative fistulae formed and number of abscess recurrences. The authors of Tonkin 2004 have calculated that to detect a difference of $10 \%$ in fistulae and abscess recurrence rates, 316 participants would be needed whilst they only included 50 .

The presentation of time-to-event data made it difficult to interpret and present here. We were concerned that Tonkin 2004 may have analysed time-to-event data with an inappropriate statistical test and there is not enough data reported for re-analysis. Ideally, time-to-event data are summarised using the median, and presented as a hazard ratio with variance data. Appropriate statistical tests, such as the log rank test, should be applied. It is also useful to present the total number of events that occurred in each group, both as useful data, and to aid potential meta-analysis of time-toevent data.

It is also important to note that in Perera 2015 blinding was not used and in Tonkin 2004 there is no report of the use of blinding, especially in relation to blinded outcome assessment. Since assess- ment of wound healing has a subjective element, the use of blinded outcome assessment in such trials would be recommended. Given the lack of reported methodological information in Tonkin 2004, we assessed the risk of detection bias as unclear, as we did selection bias. Overall, clearer reporting of trial methods would have enabled us to class risk of bias domains more usefully as high or low risk. We downgraded Perera 2015 three times due to indirectness, imprecision, and limitations in design and we classed this study at high risk of detection and performance bias.

\section{Potential biases in the review process}

The review considered as much evidence as it was possible to obtain, including studies that were not published in English. It was not possible to obtain two papers; these studies included abscesses on multiple regions of the body and were unlikely to yield significant subgroup data for perianal abscesses. A further study was only published in abstract form and it was not possible to scrutinise the data further.

\section{Agreements and disagreements with other studies or reviews}

There are no other systematic reviews of RCTs relating to packing of perianal abscesses. All the available RCTs to date have been scrutinised for this review.

\section{AUTHORS, CONCLUSIONS}

\section{Implications for practice}

There is no good quality evidence for the use of internal dressings (packing) for healing perianal abscess cavities, and yet, this is established, common practice (Nelson 2002). This review has found only two small randomised controlled trials (RCTs) which together provide very low quality evidence due to attrition, performance, and detection bias, as well as imprecision (small studies) and indirectness. Fistula formation rates, with and without packing, are not known. Given the current lack of evidence, decisions to pack may be based on local practices.

\section{Implications for research}

Further research to evaluate the healing rates by not packing perianal abscess cavities, and the potential benefit to patients of decreased wound pain is needed, alongside assessment of the safety of not packing in terms of fistula formation and abscess recurrence rates. Large, appropriately powered, robust RCTs comparing packing versus not packing of perianal abscess cavities would be the most appropriate study design, with the study population 
and setting being relevant to current standard practice and uncertainties.

\section{ACKNOW LEDGEMEN TS}

The authors would like to acknowledge the contribution of the peer referees and Cochrane Wounds editors: Susan O'Meara, Sarah Rhodes, AG Radhika and Brian Stafford (review) and Liz Bickerdike, Louise Hunt, Evan Kontopantelis, AG Radhika and Dirk Ubbink (protocol). The authors are also grateful to Clare Dooley for copy editing the protocol.

\section{R E F E R E N C E S}

\section{References to studies included in this review}

Perera 2015 \{published data only\}

Perera AP, Howell AM, Sodergren MH, Farne H, Darzi A, Purkayastha $S$, et al. A pilot randomised controlled trial evaluating postoperative packing of the perianal abscess. Langenbecks Archives of Surgery 2015;400(2):267-71.

Tonkin 2004 \{published data only\}

Tonkin DM, Murphy E, Brooke-Smith M, Hollington P, Rieger N, Hockley S, et al. Perianal abscess: a pilot study comparing packing with nonpacking of the abscess cavity. Diseases of the Colon and Rectum 2004;47(9):1510-4.

\section{References to studies excluded from this review}

Abraham 1997 \{published data only (unpublished sought but not used)\}

Abraham N, Doudle M, Carson P. Open versus closed surgical treatment of abscesses: a controlled clinical trial. Australia and New Zealand Journal of Surgery 1997;67(4): 73-6.

Alimov 2013 \{published data only (unpublished sought but not used)\} Alimov V, Lovecchio F, Sinha M, Foster KN, Drachman D. Use of a silver-containing hydrofiber dressing for filling abscess cavity following incision and drainage in the emergency department: a randomized controlled trial. Advances in Skin and Wound Care 2013;26(1):20-5.

Beck 1988 \{published data only\} Beck DE, Fazio VW, Lavery IC, Jagelman DG, Weakley FL. Catheter drainage of ischiorectal abscesses. Southern Medical Journal 1988;81(4):444-6.

Berry 1993 \{published data only\} Berry DP, Whiston RK, Bale S, Harding KG. Cavity wounds: Allevyn cavity wound dressing versus Kaltostat. Interim results of a comparative trial. Proceedings of the 2nd European Conference on Advances in Wound Management; 1992, 20-23 October; Harrogate, UK. London: Macmillan, 1993:109-10.
Butterworth 1991 \{published data only\}

Butterworth RJ, Bale S, Harding KG, Hughes LE. Allevyn cavity wound dressing: a clinical trial of 80 patients. Proceedings of the 1st European Conference on Advances in Wound Management; 1991, 4-6 September; Cardiff, UK. London: Macmillan, 1992:112-3.

Cooper 1995 \{published data only\}

* Cooper R, Bale S, Harding KG. An improved cleansing regime for a modified foam cavity dressing. Journal of Wound Care 1995;4(1):13-6.

Cooper R, Bale S, Harding KG. An improved cleansing regime for a modified foam cavity dressing. Proceedings of the 3rd European Conference on Advances in Wound Management. London: Macmillan, 1994:89-92.

Dawson 1992 \{published data only (unpublished sought but not used)\} Dawson C, Armstrong MWJ, Fulford SCV, Faruqi RM, Galland RB. Use of calcium alginate to pack abscess cavities: a controlled clinical trial. Journal of the Royal College of Surgeons of Edinburgh 1992;37(3):177-9.

Edino 2001 \{published data only (unpublished sought but not used)\} Edino ST, Ihezue CH, Obekpa PO. Outcome of primary closure of incised acute soft-tissue abscesses. Nigerian Postgraduate Medical Journal 2001;8(1):32-6.

Gajiwala 2006 \{published data only\} Gajiwala KJ. Puncture, drainage and irrigation: is that enough for treating an abscess?. Indian Journal of Plastic Surgery 2006;39:189-95.

Gibson 1994 \{published data only (unpublished sought but not used)\} Gibson C. Comparison of an alginate wound dressing (Kaltostat $2 \mathrm{~g}$ ) and ribbon gauze for the treatment of postoperative cavity wounds. Principles, Progress and Practice in Wound Care; 1994, 15-17 November; Harrogate, UK. London: Macmillan, 1994.

Guest 2005 \{published data only\} Guest JF, Ruiz FJ. Modelling the cost implications of using carboxymethylcellulose dressing compared with gauze in the management of surgical wounds healing by secondary 
intention in the US and UK. Current Medical Research and Opinion 2005;21(2):281-90.

Gupta 1992 \{published data only (unpublished sought but not used)\} Gupta R, Foster ME, Miller E. [Calcium alginate ribbon: a painless surgical pack]. Proceedings of the 1st European Conference on Advances in Wound Management; 1991 4-6 September; Cardiff, UK. London: Macmillan, 1992:112-3.

Gustafsson 2015 \{unpublished data only\} Gustafsson, K. Multicenter study for diagnosis and treatment of perianal abscesses. www.clinicaltrials.gov/ct $2 /$ show/NCT02306382 (accessed 5 September 2015).

Isbister 1987 \{published data only\} Isbister WH. A simple method for the management of anorectal abscess. Australian and New Zealand Journal of Surgery 1987;57:771-4.

Kessler 2012 \{published data only\} Kessler DO, Krantz A, Mojica M. Randomized trial comparing wound packing to no wound packing following incision and drainage of superficial skin abscesses in the pediatric emergency department. Paediatric Emergency Care 2012;28(6):514-7.

Koehler 2009 \{published data only\}

Koehler MB, Nakayama DK. Treatment of cutaneous abscesses without postoperative dressing changes. Association of Perioperative Registered Nurses Journal 2009;90 (4):569-74.

Kronborg 1984 \{published data only\}

Kronborg O, Olsen $\mathrm{H}$. Incision and drainage v. incision, curettage and suture under antibiotic cover in anorectal abscess. A randomized study with 3-year follow-up. Acta Chirurgica Scandinavica 1984;150(8):689-92.

Kyle 1990 \{published data only\}

Kyle S, Isbister WH. Management of anorectal abscesses: comparison between traditional incision and packing and de Pezzer catheter drainage. Australian and New Zealand Journal of Surgery 1990;60(2):129-31.

Leaper 1976 \{published data only\}

Leaper DJ, Page RE, Rosenberg IL, Wilson DH, Goligher JC. A controlled study comparing the conventional treatment of idiopathic anorectal abscess with that of incision, curettage and primary suture under systemic antibiotic cover. Diseases of the Colon and Rectum 1976;19 (1):46-50

Llera 1985 \{published data only\} Llera JL, Levy RC. Treatment of cutaneous abscess: a double-blind clinical study. Annals of Emergency Medicine 1985;14:15-9.

Lundhus 1993 \{published data only\}

Lundhus E, Gottrup F. Outcome of three to five years of primary closure of perianal and pilonidal abscess. European Journal of Surgery 1993;159:555-8.

Macfie 1977 \{published data only\}

Macfie J, Harvey J. The treatment of acute superficial abscesses: a prospective clinical trial. British Journal of Surgery 1977;64(4):264-6.
Meng 2005 \{published data only\}

Meng F, Wang J, Wang L, Yang X. Effect of moist dressing on wound care after abscess incision. Chinese Journal of Nosoconmiology 2005.

Moore 2000 \{published data only (unpublished sought but not used)\} Moore PJ, Foster L. Cost benefits of two dressings in the management of surgical wounds. British Journal of Nursing 2000;9(17):1128-32.

Myers 2015 \{unpublished data only\} Myers JG. Pilot study comparing Taliderm ${ }^{\mathrm{TM}}$ dressing versus standard of care for open incision and drainage of wounds. www.clinicaltrials.gov/ct2/show/NCT00686296 (accessed 5 September 2015).

O'Malley 2009 \{published data only\} O’Malley GF, Dominici P, Giraldo P, Aguilera E, Verma $\mathrm{M}$, Lares $\mathrm{C}$, et al. Routine packing of simple cutaneous abscesses is painful and probably unnecessary. Academic Emergency Medicine 2009;16(5):470-3.

Ritchie 1972 \{published data only\}

Ritchie IC. Technique to improve the rate of healing of incised abscesses. British Medical Journal 1972;2:381-3.

Simms 1982 \{published data only\} Simms MH, Curran F, Johnson RA, Oates J, Givel JC, Chabloz R, et al. Treatment of acute abscesses in the casualty department. British Medical Journal 1982;284: 1827-9.

Singer 2013 \{published data only\}

Singer AJ, Taira BR, Chale S, Bhat R, Kennedy D, Schmitz G. Primary versus secondary closure of cutaneous abscesses in the emergency department: a randomized controlled trial. Academic Emergency Medicine 2013;20(1):27-32.

Stewart 1985 \{published data only\}

Stewart MP, Laing MR, Krukowski ZH. Treatment of acute abscesses by incision, curettage and primary suture without antibiotics: a controlled clinical trial. British Journal of Surgery 1985;72(1):66-7.

Sørensen 1987 \{published data only\} Sørensen C, Hjortrup A, Moesgaard F, Lykkegaard-Nielsen $M$. Linear incision and curettage vs. deroofing and drainage in subcutaneous abscess. A randomized clinical trial. Acta Chirurgica Scandinavica 1987;153:659-60.

Ubbink 2008 \{published data only\}

Ubbink DT, Vermeulen H, Goossens A, Kelner RB, Schreuder SM, Lubbers MJ. Occlusive vs gauze dressings for local wound care in surgical patients: a randomized clinical trial. Archives of Surgery 2008;143(10):950-5.

Williams 1995 \{published data only\} Williams P, Foster ME, Howells REJ, Miller E, Haray PN. A comparison of two alginate dressings in the management of acute wound cavities. Proceedings of the 4th European Conference on Advances in Wound Management. London: Macmillan, 1995:55-6. 
Wilson 1964 \{published data only\}

Wilson D. The late results of anorectal abscess treated by incision, curettage and primary suture under antibiotic cover. British Journal of Surgery 1964;51:828-31.

Wu 2008 \{published data only (unpublished sought but not used)\} Wu G, Liu F, Zhang C, He Q, Wang W, Gu Q. Study on treating residual cavity of body surface after abscess drainage by sodium hyaluronate hydrogel [Zhongguo xiu fu chong jian wai ke za zhi]. Chinese Journal of Reparative and Reconstructive Surgery 2008;22(9):1082-4.

Young 1982 \{published data only\}

Young HL, Wheeler MH. Report of a prospective trial of dextranomer beads (Debrisan) and silicone foam elastomer (Silastic) dressings in surgical wounds. British Journal of Surgery 1982;69(1):33-4.

\section{References to ongoing studies}

\section{NCT01897675 \{unpublished data only\}}

Schechter-Perkins E. A comparison of techniques for treating skin abscesses (LoopDrainage). www.clinicaltrials.gov/ct2/ show/NCT01897675 (accessed 5 September 2015).

\section{NCT02286479 \{unpublished data only\}}

Ozturan IU. Comparison of loop and primary incision $\&$ drainage techniques in the emergency department. www.clinicaltrials.gov/ct2/show/NCT02286479 (accessed 5 September 2015)

\section{Additional references}

\section{Barnes 1988}

Barnes S, Milsom P. Abscesses: an open and shut case!. Archives of Emergency Medicine 1988;5:200-5.

\section{Deeks 2002}

Deeks JJ. Issues in the selection of a summary statistic for meta-analysis of clinical trials with binary outcomes. Statistics in Medicine 2002;21:1575-600.

\section{Eisenhammer 1978}

Eisenhammer $S$. The final evaluation and classification of the surgical treatment of the primary anorectal, cryptoglandular intermuscular (intersphincteric) fistulous abscess and fistula. Diseases of the Colon and Rectum 1978;21:237-54.

\section{Ellis 1960}

Ellis M. Incision and primary suture of abscesses of the anal region. Proceedings of the Royal Society of Medicine 1960;53 (8):652-3.

Fitch 2007

Fitch M, Manthey D, McGinnis H, Nicks B, Pariyadath M. Abscess incision and drainage. New England Journal of Medicine 2007;357(19):e20.

\section{Goligher 1984}

Goligher JC, Duthie HL, Nixon HH. Surgery of the Anus, Rectum and Colon. 5th Edition. London: Bailliere Tindall, 1984.

\section{Hamadani 2009}

Hamadani A, Haigh PI, Liu IL, Abbas MA. Who is at risk for developing chronic anal fistula or recurrent anal sepsis after initial perianal abscess?. Diseases of the Colon and Rectum 2009;52:217-21.

\section{Higgins 2003}

Higgins JP, Thompson SG, Deeks JJ, Altman DG. Measuring inconsistency in meta-analyses. BMJ 2003;327 (7414):557-60.

\section{Higgins 2011a}

Higgins JPT, Altman DG, Sterne, JAC. Chapter 8: Assessing risk of bias in included studies. In: Higgins JPT, Green S (editors). Cochrane Handbook for Systematic Reviews of Interventions. Version 5.1.0 [updated March 2011]. The Cochrane Collaboration, 2011. Available from www.cochrane-handbook.org.

\section{Higgins 2011b}

Deeks JJ, Higgins JPT, Altman DG. Chapter 9: Analysing data and undertaking meta-analyses. In: Higgins JPT, Green S (editors). Cochrane Handbook for Systematic Reviews of Interventions Version 5.1.0 (updated March 2011). The Cochrane Collaboration, 2011. Available from www.cochrane-handbook.org.

Kontopantelis 2013

Kontopantelis E, Springate DA, Reeves D. A re-analysis of the Cochrane Library data: the dangers of unobserved heterogeneity in meta-analyses. PLoS One 2013;26:e69930.

Lefebvre 2011

Lefebvre C, Manheimer E, Glanville J. Chapter 6: Searching for studies. In: Higgins JPT, Green S (editors). Cochrane Handbook for Systematic Reviews of Interventions Version 5.1.0 [updated March 2011]. The Cochrane Collaboration, 2011. Available from www.cochrane-handbook.org.

Liberati 2009

Liberati A, Altman DG, Tetzlaff J, Mulrow C, Gøtzsche PC, Ioannidis JP, et al. The PRISMA statement for reporting systematic reviews and meta-analyses of studies that evaluate health care interventions: explanation and elaboration. BMJ 2009;339:b2700.

Lohsiriwat 2010

Lohsiriwat V, Yodying H, Lohsiriwat D. Incidence and factors influencing the development of fistula-in-ano after incision and drainage of perianal abscesses. Journal of the Medical Association of Thailand 2010;93(1):61-5.

\section{Malik 2010}

Malik AI, Nelson RL, Tou S. Incision and drainage of perianal abscess with or without treatment of anal fistula. Cochrane Database of Systematic Reviews 2010, Issue 7. [DOI: $10.1002 / 14651858 . C D 006827]$

\section{Milne 2010}

Milne K, Carpenter C. Abscesses: to pack or not to pack? Emergency Physicians Monthly. epmonthly.com/article/ abscesses-to-pack-or-not-to-pack/ (accessed 5 September 2015).

\section{Mortensen 1995}

Mortensen J, Kraglund K, Klaerke M, Jaeger G, Svane S, Boné J. Primary suture of anorectal abscess. A randomized study comparing treatment with Clindamycin 
vs. Clindamycin and Gentacoll. Diseases of the Colon and Rectum 1995;38(4):398-401.

\section{Nelson 1985}

Nelson RL, Prasad L, Abcarian H. Anal carcinoma presenting as a perirectal abscess or fistula. Archives of Surgery 1985;120:632-5.

Nelson 2002

Nelson R. Anorectal abscess fistula: what do we know?. Surgical Clinics of North America 2002;82:1139-51.

Ommer 2012

Ommer A, Herold A, Berg E, Fürst A, Sailer M, Schiedeck T. German S3 guideline: anal abscess. International Journal of Colorectal Disease 2012;27(6):831-7.

\section{Parks 1961}

Parks AG. The pathogenesis and treatment of fistula-in-ano. British Medical Journal 1961;1(5224):463-9.

Parks 1976

Parks AG, Gordon PH, Hardcastle JD. A classification of fistula-in-ano. British Journal of Surgery 1976;63:1-12.

\section{Phillips 1997}

Phillips RKS, Lunniss PJ. Anorectal sepsis. In: Nicholls RJ, Dozois RR editor(s). Surgery of the Colon and Rectum. New York: Churchill Livingstone, 1997:255-84.

\section{Ramanujam 1984}

Ramanujam PS, Prasad ML, Abcarian H, Tan AB. Perianal abscess and fistulas; a study of 1023 patients. Diseases of the Colon and Rectum 1984;27:593-7.

\section{Read 1979}

Read DR, Abcarian H. A prospective survey of 474 patients with anorectal abscess. Diseases of the Colon and Rectum 1979;22(8):566-8.

\section{RevMan 2014 [Computer program]}

The Nordic Cochrane Centre, The Cochrane Collaboration. Review Manager (RevMan). Version 5.3. Copenhagen: The Nordic Cochrane Centre, The Cochrane Collaboration, 2014.

\section{Sangwan 1996}

Sangwan YP, Schoetz DJ Jr, Murray JJ, Roberts PL, Coller JA. Perianal Crohn's disease. Results of local surgical treatment. Diseases of the Colon and Rectum 1996;39(5): 529-35.

\section{Schunemann 2011a}

Schünemann HJ, Oxman AD, Higgins JPT, Vist GE, Glasziou P, Guyatt GH. Chapter 11: Presenting results and 'Summary of findings' tables. In: Higgins JPT, Green $S$ (editors). Cochrane Handbook for Systematic Reviews of Interventions Version 5.1.0 [updated March 2011]. The Cochrane Collaboration, 2011. Available from www.cochrane-handbook.org.

\section{Schunemann 2011b}

Schünemann HJ, Oxman AD, Vist GE, Higgins JPT, Deeks JJ, Glasziou P, et al. Chapter 12: Interpreting results and drawing conclusions. In: Higgins JPT, Green $S$ (editors). Cochrane Handbook for Systematic Reviews of Interventions Version 5.1.0 [updated March 2011]. The Cochrane Collaboration, 2011. Available from www.cochrane-handbook.org.

\section{SIGN 2015}

Scottish Intercollegiate Guidelines Network (SIGN). Search filters. www.sign.ac.uk/methodology/filters.html\#random (accessed 5 September 2015).

\section{Steele 2011}

Steele SR, Kumar R, Feingold DL, Rafferty JL, Buie WD, Standards Practice Task Force of the American Society of Colon and Rectal Surgeons. Practice parameters for the management of perianal abscess and fistula-in-ano. Diseases of the Colon and Rectum 2011;54(12):1465-74.

\section{Tang 1996}

Tang CL, Chew SP, Seow-Choen F. Prospective randomized trial of drainage alone versus drainage and fistulotomy for acute perianal abscesses with proven internal opening. Diseases of the Colon and Rectum 1996;39(12):1415-7.

\section{Tejirian 2005}

Tejirian T, Abbas M. Sitz bath: where is the evidence? Scientific basis of a common practice. Diseases of the Colon and Rectum 2005;48(12):2336-40.

\section{Vasilevsky 1984}

Vasilevsky CA, Gordon PH. The incidence of recurrent abscesses or fistula-in-ano following anorectal suppuration. Diseases of the Colon and Rectum 1984;27(2):126-30.

\section{Whiteford 2007}

Whiteford, MH. Perianal abscess/fistula disease. Clinics in Colon and Rectal Surgery 2007;20(2):102-9.

\section{Williams 2007}

Williams JG, Farrands PA, Williams AB, Taylor BA, Lunniss PJ, Sagar PM, et al. The treatment of anal fistula: ACPGBI position statement. Colorectal Disease 2007;9(Suppl 4): $18-50$.

* Indicates the major publication for the study 


\section{CHARACTERISTICS OF STUDIES}

\section{Characteristics of included studies [ordered by study ID]}

\section{Perera 2015}

\begin{tabular}{|c|c|}
\hline Methods & $\begin{array}{l}\text { Two-arm randomised controlled trial with randomisation of 'the majority of participants' } \\
\text { after first dressing change } \\
\text { Single centre in UK } \\
\text { Duration of follow-up was fortnightly until healing had occurred or a minimum of } 6 \\
\text { months or if a recurrent abscess or fistula formed }\end{array}$ \\
\hline Participants & $\begin{array}{l}\text { Number of participants randomised }=14 \\
\text { Number of participants analysed = } 14 \\
\text { Inclusion criteria: } \\
\text { - participants aged }>18 \text { years with an anorectal abscess } \\
\text { Exclusion criteria: } \\
\text { - participants aged }<18 \text { years } \\
\text { - participants with abscesses associated with Crohn's disease or other underlying } \\
\text { causes, including known fistulae } \\
\text { - abscesses in which initial drainage was considered inadequate } \\
\text { - participants unable to give informed consent } \\
\text { Baseline details: } \\
63 \% \text { ( } 5 / 8 \text { ) of participants were male in the packing group and } 33 \% \text { ( } 2 / 6) \text { in the non- } \\
\text { packing group } \\
\text { Median age was } 47 \text { years (IQR = } 17 \text { ) in the packing group and } 48 \text { years (IQR = } 7 \text { ) in } \\
\text { the non-packing group } \\
\text { Median duration of symptoms: } 4 \text { days in packing group, } 6 \text { days in non-packing group } \\
\text { Abscesses were classified as superficial or deep, although no details are given on how } \\
\text { this classification has been made. } 37.5 \% \text { were classified by study authors as deep in the } \\
\text { packing groups and } 33.3 \% \text { in the non-packing group } \\
\text { Median incision size was } 30 \mathrm{~mm} \text { (IQR = } 15 \text { ) in the packing group and } 30 \text { mm (IQR = } \\
17.5 \text { ) in the non-packing group }\end{array}$ \\
\hline
\end{tabular}

Interventions

Both groups underwent incision and drainage under general anaesthetic. No operative details are given, except noting that a haemostatic pack was placed at the end of the operation

Randomisation on day 1 post-operatively

Packing group: dressing changed in hospital on day 1 and care transferred to community nursing teams for daily dressings in their own home $(\mathrm{n}=8)$

Non-packing group: dressing removed on day 1 in hospital and superficial protective/ absorptive dressing applied. No community nursing team involvement $(n=6)$

Outcomes Primary outcome: median time to healing (defined as complete re-epithelialisation of the wound)

Secondary outcomes:

- median pain scores

- post-operative fistula formation

- abscess recurrence 
Perera 2015 (Continued)

$\begin{array}{lll}\text { Notes } & \text { Funding source: no funding used for the study }\end{array}$

Risk of bias

\begin{tabular}{|c|c|c|}
\hline Bias & Authors' judgement & Support for judgement \\
\hline $\begin{array}{l}\text { Random sequence generation (selection } \\
\text { bias) }\end{array}$ & Low risk & $\begin{array}{l}\text { Quote: "Patients were randomly assigned } \\
\text { to receive either packing or no packing } \\
\text { through allocation by sealed envelope de- } \\
\text { rived from a computer-generated randomi- } \\
\text { sation sequence, which was carried out by } \\
\text { a member of the study team" } \\
\text { Comment: Computer-generated randomi- } \\
\text { sation sequence }\end{array}$ \\
\hline Allocation concealment (selection bias) & Unclear risk & $\begin{array}{l}\text { Quote: "Patients were randomly assigned } \\
\text { to receive either packing or no packing } \\
\text { through allocation by sealed envelope de- } \\
\text { rived from a computer-generated randomi- } \\
\text { sation sequence, which was carried out by } \\
\text { a member of the study team" } \\
\text { Comment: Lack of detail on whether en- } \\
\text { velopes were numbered and sequentially } \\
\text { ordered to ensure adequate allocation con- } \\
\text { cealment }\end{array}$ \\
\hline
\end{tabular}

Blinding of participants and personnel High risk (performance bias)

Quote: "Due to the nature of the intervenAll outcomes tion, it was not possible for the participants or the investigators to be blinded" Comment: Blinding was not feasible, therefore study at high risk of bias

Blinding of outcome assessment (detection High risk bias)

Quote: "Due to the nature of the intervenAll outcomes tion, it was not possible for the participants or the investigators to be blinded" Comment: Blinding was not feasible, therefore study at high risk of bias

Incomplete outcome data (attrition bias) Low risk All outcomes

Quote: "Fifteen patients were eligible for inclusion and 14 were enrolled......No subjects were lost to follow-up. All follow-up reviews were conducted in person with no telephone interviews carried out....No adverse or unexpected events were seen in either group"

Comment: No loss of follow-up, no withdrawals, all follow-up conducted in person, no intervention discontinued, no adverse 
Perera 2015 (Continued)

events

\begin{tabular}{l|l} 
Selective reporting (reporting bias) $\quad$ Low risk & $\begin{array}{l}\text { Comment: All outcomes recorded in the } \\
\text { trial methods were reported }\end{array}$
\end{tabular}

Other bias

Unclear risk

Quote: "The majority of patient recruitment was performed postoperatively following incision and drainage, and prior to any dressing change"

Comment: Unclear how many patients were recruited pre-operatively or the impact of this

Tonkin 2004

Methods

Two-arm randomised controlled trial with randomisation after first dressing change Single centre in Australia

Duration of follow-up was fortnightly until healing had occurred or a recurrent abscess or fistula formed

Participants

Number of participants randomised $=50$

Number of participants analysed $=43$ (7 lost to follow-up)

Inclusion criteria:

- participants aged $>18$ years with an anorectal abscess

Exclusion criteria:

- participants aged $<18$ years

- participants with abscesses associated with Crohn's disease or other underlying causes

- abscesses in which initial drainage was considered inadequate

- participants unable to give informed consent

Baseline details:

$85 \%$ of participants were male in the packing group and $78 \%$ in the non-packing group The median age was 33 years in both groups (range 21-58 in packing group, 19-65 in the non-packing group)

Abscesses were classified as superficial (submucosal) or deep (ischiorectal/intersphincteric). Both groups had 7 deep abscesses

Median abscess size was $30 \mathrm{~mm}$ in each group and there were no significant differences between the groups in the location of the abscess

Median duration of symptoms: 4 days in packing group, 3 days in non-packing group Fistula laid open at initial operation in 6 participants: 2 in packing group, 4 in nonpacking group. One fistula in packing group detected at operation but is unaccounted for in the trial report

Length of hospital stay was a median of 1 day in both groups

Interventions

Both groups: standard operative technique of de-roofing abscess cavity (elliptical incision) under general anaesthetic and packing with gauze or calcium alginate for haemostasis. Low fistulae were laid open at the time of surgery at the discretion of treating surgeon. Randomisation on day 1 post-operatively

Packing group: dressing changed in hospital on day 1 and care transferred to community 
Tonkin 2004 (Continued)

nursing teams for daily dressings in their own home $(\mathrm{n}=23)$

Non-packing group: dressing removed on day 1 in hospital and superficial protective/ absorptive dressing applied. No community nursing team involvement $(\mathrm{n}=27)$

Outcomes

Primary outcome: median time to healing (defined as complete re-epithelialisation of the wound)

Secondary outcomes:

- median pain scores

- post-operative fistula formation

- abscess recurrence

- post-operative morphine requirement whilst inpatient

- length of hospital stay

Notes

Funding source: funding source not stated

\section{Risk of bias}

Bias

Random sequence generation (selection Unclear risk bias)
Authors' judgement
Allocation concealment (selection bias) Unclear risk

\section{Support for judgement}

Quote: "On the first post-operative day... patients were provided with written information on the trial protocol, and informed written consent was obtained. Patients were then randomised to packing and nonpacking groups using a sealed envelope system" Comment: No information on how randomisation sequence was generated

Blinding of participants and personnel Unclear risk (performance bias)

All outcomes

Blinding of outcome assessment (detection Unclear risk bias)

All outcomes
Quote: "On the first post-operative day, before any change of dressing, patients who fulfilled the inclusion criteria were invited to enrol in the study...Patients were then randomised to packing and nonpacking groups using a sealed envelope system" Comment: Lack of detail on whether envelopes were numbered and sequentially ordered to ensure adequate allocation concealment

Comment: There is no record of the use of blinding in this study

Quote: "Patients were reviewed at two weekly intervals in the outpatient clinic until cavity healing was apparent. Healing was defined as the cavity being closed and the skin completely re-epithelialized"

Comment: There is no record of the use of 
Tonkin 2004 (Continued)

blinding in this study

\begin{tabular}{l|l|l}
$\begin{array}{l}\text { Incomplete outcome data (attrition bias) } \\
\text { All outcomes }\end{array}$ & High risk & $\begin{array}{l}\text { Quote: "Fifty patients were enrolled in the } \\
\text { study...Seven were lost to follow-up (3 in } \\
\text { the packing and } 4 \text { in the nonpacking arm) } \\
\text {. Of the } 43 \text { participants suitable for anal- } \\
\text { ysis, } 20 \text { participants were allocated to the } \\
\text { packing group and } 23 \text { to the nonpacking } \\
\text { group" } \\
\text { Comment: Data on } 14 \% \text { of participants } \\
\text { seems to have been excluded from the anal- } \\
\text { yses. These missing data were considered to } \\
\text { have substantial impact on the results }\end{array}$ \\
\hline Selective reporting (reporting bias) & Low risk & $\begin{array}{l}\text { Comment: All outcomes recorded in the } \\
\text { trial methods were reported }\end{array}$ \\
\hline Other bias & Unclear risk & $\begin{array}{l}\text { Comment: Ommission of a participant } \\
\text { from the time to healing analysis. The im- } \\
\text { pact of this is unclear }\end{array}$
\end{tabular}

$\mathrm{IQR}$ = interquartile range

Characteristics of excluded studies [ordered by study ID]

\begin{tabular}{ll}
\hline Study & Reason for exclusion \\
\hline Abraham 1997 & Unable to obtain a subgroup analysis for perianal abscesses \\
\hline Alimov 2013 & Unable to obtain a subgroup analysis for perianal abscesses \\
\hline Beck 1988 & Non-randomised study \\
\hline Berry 1993 & Perianal abscesses not included in the study \\
\hline Butterworth 1991 & Perianal abscesses not included in the study \\
\hline Cooper 1995 & Perianal abscesses not included in the study \\
\hline Dawson 1992 & Unable to obtain a subgroup analysis for perianal abscesses \\
\hline Edino 2001 & Unable to obtain paper \\
\hline Gajiwala 2006 & Non-randomised study \\
\hline $\begin{array}{l}\text { Internal dressings for healing perianal abscess cavities (Review) } \\
\text { Copyright } \odot 2016 \text { The Cochrane Collaboration. Published by John Wiley \& Sons, Ltd. }\end{array}$ \\
\hline
\end{tabular}


(Continued)

\begin{tabular}{|c|c|}
\hline Gibson 1994 & Published in abstract form only \\
\hline Guest 2005 & Non-randomised study \\
\hline Gupta 1992 & Unable to obtain a subgroup analysis for perianal abscesses \\
\hline Gustafsson 2015 & Inappropriate comparator intervention \\
\hline Isbister 1987 & Non-randomised study \\
\hline Kessler 2012 & Perianal abscesses not included in the study \\
\hline Koehler 2009 & Perianal abscesses not included in the study \\
\hline Kronborg 1984 & Inappropriate comparator intervention \\
\hline Kyle 1990 & Non-randomised study \\
\hline Leaper 1976 & Inappropriate comparator intervention \\
\hline Llera 1985 & Irrelevant intervention \\
\hline Lundhus 1993 & Non-randomised study \\
\hline Macfie 1977 & Unable to obtain a subgroup analysis for perianal abscesses \\
\hline Meng 2005 & Unable to obtain paper \\
\hline Moore 2000 & Unable to obtain a subgroup analysis for perianal abscesses \\
\hline Myers 2015 & Perianal abscesses not included in the study \\
\hline O’Malley 2009 & Perianal abscesses not included in the study \\
\hline Ritchie 1972 & Non-randomised study \\
\hline Simms 1982 & Unable to obtain a subgroup analysis for perianal abscesses \\
\hline Singer 2013 & Perianal abscesses not included \\
\hline Stewart 1985 & Unable to obtain a subgroup analysis for perianal abscesses \\
\hline Sørensen 1987 & Inappropriate comparator intervention \\
\hline Ubbink 2008 & Perianal abscesses not included in the study \\
\hline Williams 1995 & Unable to obtain a subgroup analysis for perianal abscesses \\
\hline
\end{tabular}


(Continued)

\begin{tabular}{ll}
\hline Wilson 1964 & Non-randomised study \\
\hline Wu 2008 & Unable to obtain a subgroup analysis for perianal abscesses \\
\hline Young 1982 & Perianal abscesses not included in the study \\
\hline
\end{tabular}

Characteristics of ongoing studies [ordered by study ID]

\section{NCT01897675}

\begin{tabular}{|c|c|}
\hline Trial name or title & $\begin{array}{l}\text { Is loop drainage of a cutaneous abscess in the Emergency Department as effective as incision and drainage } \\
\text { with packing? }\end{array}$ \\
\hline Methods & $\begin{array}{l}\text { Two-arm randomised controlled trial with randomisation prior to treatment } \\
\text { Single centre in USA } \\
\text { Duration of follow-up is } 14 \text { days } \\
\text { Outcome assessor blinded }\end{array}$ \\
\hline Participants & $\begin{array}{l}\text { Aim to enrol } 216 \text { participants } \\
\text { Inclusion criteria: } \\
\text { - Adult patient over } 18 \text { years of age } \\
\text { - Presenting to the Boston Medical Center main Emergency Department or Urgent Care area for initial } \\
\text { treatment of a skin abscess } \\
\text { - English-speaking } \\
\text { - Able to provide written informed consent } \\
\text { - Willing to return in } 14 \text { days for follow-up visit } \\
\text { - Able to give a telephone number for follow-up contact } \\
\text { Exclusion criteria: } \\
\text { - Previously treated for this abscess } \\
\text { - Altered mental status } \\
\text { - Patients with active psychiatric issues that preclude their ability to provide informed consent } \\
\text { - Previously enrolled in the study } \\
\text { - Abscess is not amenable to treatment by an Emergency Physician in the Emergency Department } \\
\text { - Abscess is post-operative or post-procedure } \\
\text { - Clinician determines abscess is not amenable to drainage by particular method } \\
\text { - Abscess is too small for packing or loop } \\
\text { - Need for hospital admission }\end{array}$ \\
\hline
\end{tabular}

Interventions

Standard intervention group undergo incision and drainage with packing of the abscess cavity, using an incision and drainage with packing (wick) placement. Packing is changed every 2-3 days, at the discretion of the treating clinician, until abscess is considered resolved

Loop drainage group: two (or more) stab incisions are made in the abscess and the cavity is probed and pus is drained. A vessel loop (elasticated plastic string) is inserted and tied off. The patient manipulates the loop 3 times per day, and removes the loop when all redness is gone and no more pus is present 


\section{NCT01897675 (Continued)}

\begin{tabular}{|c|c|}
\hline Outcomes & $\begin{array}{l}\text { Primary outcome measure: } \\
\text { - Abscess resolution at } 14 \text { days } \\
\text { Secondary outcome measures: } \\
\text { - Patient satisfaction immediately after procedure: How satisfied is patient immediately after procedure } \\
\text { (Likert scale)? Did patient feel discomfort during procedure (Likert scale)? } \\
\text { - Cosmetic outcome at } 14 \text { days: Appearance according to wound scale, presence or absence of: step-off } \\
\text { of borders, contour irregularities, wound margin separation, edge inversion, excessive distortion, overall } \\
\text { appearance } \\
\text { - Patient satisfaction at } 14 \text { days with: number of follow-up visits (Likert scale), cosmetic appearance } \\
\text { (Likert scale), pain (Likert scale), overall abscess care (Likert scale) } \\
\text { - Number of follow-up visits to either Emergency Department or outpatient clinic for abscess care at } 14 \\
\text { days } \\
\text { - Number of complications at } 14 \text { days: need for new incision in the same abscess, extension of the } \\
\text { original incision, starting antibiotics, changing antibiotics, admission to hospital }\end{array}$ \\
\hline Starting date & August 2013 \\
\hline Contact information & Elissa Schechter-Perkins, MD, MPH. elissa.schechter@bmc.org \\
\hline
\end{tabular}

\section{NCT02286479}

Trial name or title Comparison of loop drainage and primary incision and drainage techniques in patients with cutaneous abscess in the Emergency Department

Methods Two-arm randomised controlled trial with randomisation prior to treatment

Single centre in Turkey

Duration of follow-up unclear

Outcome assessor blinded

Participants

Aim to enrol 60 participants

Inclusion criteria:

- Adult patients presenting to Kocaeli University Emergency Department with cutaneous abscess

- Able to provide written informed consent

Exclusion criteria:

- Under 18 years of age

- Patients who are immunosuppressed

- Using medications that have effects on wound healing

- Abscess is not recognisable by bedside ultrasound

- Lidocaine allergy

Interventions Standard intervention group undergo incision and drainage

Experimental intervention group undergo loop drainage

No further details are given 


\section{NCT02286479 (Continued)}

\begin{tabular}{l|l}
\hline Outcomes & $\begin{array}{l}\text { Primary outcome measure: } \\
\text { - Abscess resolution at 7 days } \\
\text { Secondary outcome measures: } \\
\text { - Procedure time } \\
\text { - Procedure pain intensity }\end{array}$ \\
\hline Starting date & October 2014 \\
\hline Contact information & Ibrahim Ulas Ozturan, MD ozturan.iu@gmail.com \\
\hline Notes & \\
\hline
\end{tabular}


DATA ANDANALYSES

Comparison 1. Packing compared with no packing

\begin{tabular}{lccll} 
Outcome or subgroup title & $\begin{array}{c}\text { No. of } \\
\text { studies }\end{array}$ & $\begin{array}{c}\text { No. of } \\
\text { participants }\end{array}$ & Statistical method & Effect size \\
\hline 1 Time to wound healing & 1 & 14 & Mean Difference (IV, Fixed, 95\% CI) & $7.30[-2.24,16.84]$ \\
2 Fistula formation & 2 & 57 & Risk Ratio (M-H, Fixed, 95\% CI) & $2.31[0.56,9.45]$ \\
3 Abscess recurrence & 2 & 57 & Risk Ratio (M-H, Fixed, 95\% CI) & $0.72[0.22,2.37]$ \\
\hline
\end{tabular}

Analysis I.I. Comparison I Packing compared with no packing, Outcome I Time to wound healing.

Review: Internal dressings for healing perianal abscess cavities

Comparison: I Packing compared with no packing

Outcome: I Time to wound healing

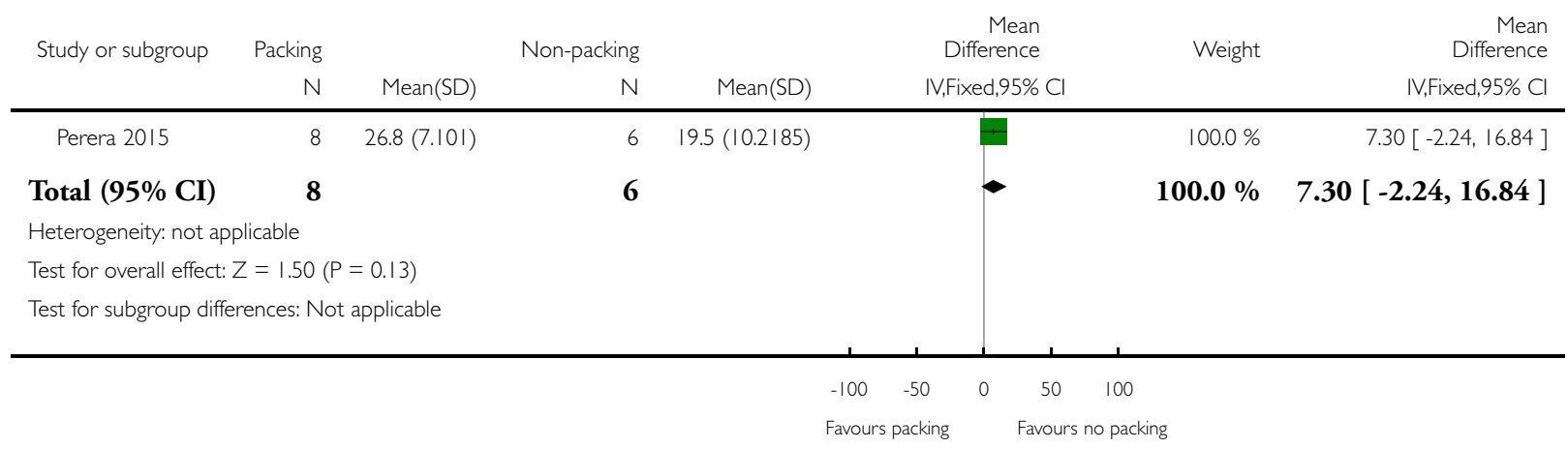




\section{Analysis I.2. Comparison I Packing compared with no packing, Outcome 2 Fistula formation.}

Review: Internal dressings for healing perianal abscess cavities

Comparison: I Packing compared with no packing

Outcome: 2 Fistula formation

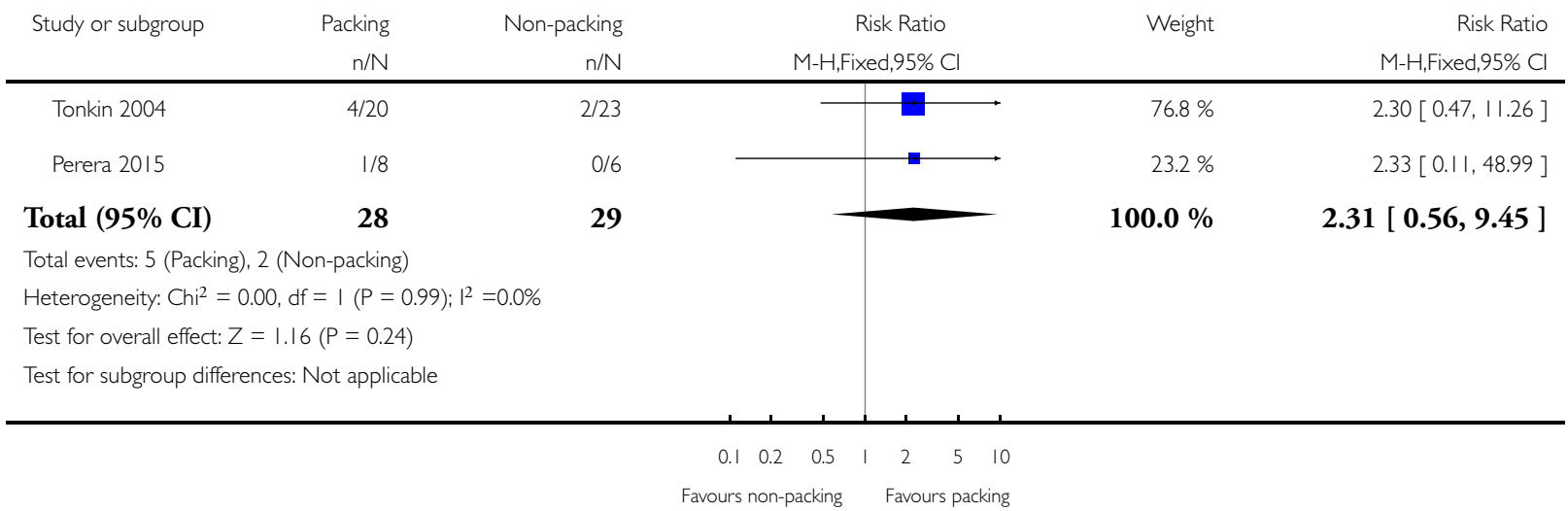

Analysis I.3. Comparison I Packing compared with no packing, Outcome 3 Abscess recurrence.

Review: Internal dressings for healing perianal abscess cavities

Comparison: I Packing compared with no packing

Outcome: 3 Abscess recurrence

\begin{tabular}{|c|c|c|c|c|c|}
\hline \multirow[t]{2}{*}{ Study or subgroup } & Packing & Non-packing & Risk Ratio & Weight & Risk Ratio \\
\hline & $\mathrm{n} / \mathrm{N}$ & $n / N$ & M-H,Fixed,95\% Cl & & M-H,Fixed,95\% Cl \\
\hline Perera 2015 & $3 / 8$ & $2 / 6$ & & $45.0 \%$ & $1.13[0.27,4.76]$ \\
\hline Tonkin 2004 & $1 / 20$ & $3 / 23$ & & $55.0 \%$ & $0.38[0.04,3.40]$ \\
\hline
\end{tabular}

Total (95\% CI)

28

29

$100.0 \%$

$0.72[0.22,2.37]$

Total events: 4 (Packing), 5 (Non-packing)

Heterogeneity: $\mathrm{Chi}^{2}=0.69, \mathrm{df}=\mathrm{I}(\mathrm{P}=0.4 \mathrm{I}) ; \mathrm{I}^{2}=0.0 \%$

Test for overall effect: $Z=0.54(P=0.59)$

Test for subgroup differences: Not applicable

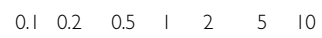

Favours non-packing Favours packing 


\section{A P P E N D I C E S}

\section{Appendix I. Search strategies}

The Cochrane Central Register of Controlled Trials (CENTRAL)

\#1 MeSH descriptor: [Soft Tissue Infections] explode all trees

\#2 soft tissue infection* or skin infection*:ti,ab,kw (Word variations have been searched)

\#3 ((wound* ${ }^{*}$ or site* or incision*) near/5 infect*):ti,ab,kw

\#4 (Sepsis or sepses or suppurat*):ti,ab,kw

\#5 MeSH descriptor: [Abscess] explode all trees

\#6 ((Anorectal or anal or rectal or rectum or perianal or perirectal or ischiorectal or intersphincteric or supralevator) near abscess*):

ti,ab,kw

\#7 (cavity or cavities):ti,ab,kw

$\# 8$ \{or \#1-\#7\}

\#9 MeSH descriptor: [Surgical Wound Infection] explode all trees

\#10 MeSH descriptor: [Surgical Wound Dehiscence] explode all trees

\#11 (surg* near/5 infect*):ti,ab,kw

\#12 (surg* near/5 wound*):ti,ab,kw

\#13 (surg* near/5 site*):ti,ab,kw

\#14 (surg* near/5 incision*):ti,ab,kw

\#15 (surg* near/5 dehisc*):ti,ab,kw

\#16 (wound* near/5 dehisc*):ti,ab,kw

\#17 (wound* near/5 infect*):ti,ab,kw

\#18 (wound near/5 disruption*):ti,ab,kw

\#19 (wound next complication*):ti,ab,kw

\#20 \{or \#9-\#19\}

\#21 (intent* or second* or heal* or complic*):ti,ab,kw

\#22 ((open* or clos*) near/5 wound*):ti,ab,kw

\#23 \{or \#21-\#22\}

$\# 24$ and \#20,\#23\}

\#25 MeSH descriptor: [Occlusive Dressings] explode all trees

\#26 MeSH descriptor: [Bandages, Hydrocolloid] explode all trees

\#27 MeSH descriptor: [Biological Dressings] explode all trees

\#28 MeSH descriptor: [Alginates] explode all trees

\#29 MeSH descriptor: [Hydrogels] explode all trees

\#30 MeSH descriptor: [Silver] explode all trees

\#31 MeSH descriptor: [Silver Sulfadiazine] explode all trees

\#32 MeSH descriptor: [Honey] explode all trees

\#33 (dressing* or hydrocolloid* or alginate* or hydrogel* or "foam" or "bead" or "film" or "films" or tulle or gauze or non-adherent or "non adherent" or silver or honey or matrix):ti,ab,kw

\#34 \{or \#25-\#33\}

$\# 35$ and \#8, \#24, \#34\} in Trials

Ovid MEDLINE

1 exp Soft Tissue Infections/

2 (soft tissue infection* or skin infection*).tw.

3 ((wound* or site* or incision*) adj5 infect*).tw.

4 (Sepsis or sepses or suppurat*).mp. [mp=title, abstract, original title, name of substance word, subject heading word, keyword heading word, protocol supplementary concept word, rare disease supplementary concept word, unique identifier]

5 exp Abscess/

6 ((Anorectal or anal or rectal or rectum or perianal or perirectal or ischiorectal or intersphincteric or supralevator) adj5 abscess*).tw. 7 ((Anorectal or anal or rectal or rectum or perianal or perirectal or ischiorectal or intersphincteric or supralevator) adj5 absess*).tw.

8 (cavity or cavities).tw.

9 or $/ 1-8$

Internal dressings for healing perianal abscess cavities (Review)

Copyright @ 2016 The Cochrane Collaboration. Published by John Wiley \& Sons, Ltd. 
10 exp Surgical Wound Infection/

11 exp Surgical Wound Dehiscence/

12 (surg* adj5 infect*).tw.

13 (surg* adj5 wound*).tw.

14 ( surg* $^{*}$ adj5 site*).tw.

15 (surg* $^{*}$ adj5 incision*).tw.

16 (surg* $^{*}$ adj 5 dehisc*).tw.

17 (wound* adj5 dehisc*).tw.

18 (wound* $^{*}$ adj5 infect*).tw.

19 (wound adj5 disrupt*).tw.

20 wound complication*.tw.

21 or/10-20

22 (intent* or second* or heal* or complic*).tw.

23 ((open* or clos*) adj5 wound*).tw.

24 or/ $22-23$

2521 and 24

26 exp Bandages/

27 exp Hydrogels/

28 exp Alginates/

29 exp Silver/

30 exp Sulfadiazine Silver/

31 exp Honey/

32 (dressing* $^{*}$ or hydrocolloid* or alginate* or hydrogel* or foam or bead or film or films or tulle or gauze or non-adherent or non adherent or silver or honey or matrix).tw.

33 or/26-32

349 and 25 and 33

35 randomized controlled trial.pt.

36 controlled clinical trial.pt.

37 randomi?ed.ab.

38 placebo.ab.

39 clinical trials as topic.sh.

40 randomly.ab.

41 trial.ti.

42 or/35-41

43 exp animals/ not humans.sh.

4442 not 43

4534 and 44

\section{Ovid EMBASE}

1 exp Soft Tissue Infections/

2 (soft tissue infection* or skin infection*).tw.

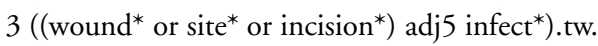

4 (Sepsis or sepses or suppurat*).mp. [mp=title, abstract, subject headings, heading word, drug trade name, original title, device manufacturer, drug manufacturer, device trade name, keyword]

5 exp Abscess/

6 ((Anorectal or anal or rectal or rectum or perianal or perirectal or ischiorectal or intersphincteric or supralevator) adj5 abscess*).tw.

7 ((Anorectal or anal or rectal or rectum or perianal or perirectal or ischiorectal or intersphincteric or supralevator) adj5 absess*).tw.

8 (cavity or cavities).tw.

9 or/1-8

10 exp Surgical Infection/

11 exp Wound Dehiscence/

12 (surg* adj5 infect*).tw.

13 (surg* $^{*}$ adj5 wound*).tw.

14 ( surg* $^{*}$ adj5 site*).tw.

Internal dressings for healing perianal abscess cavities (Review)

Copyright () 2016 The Cochrane Collaboration. Published by John Wiley \& Sons, Ltd. 
15 (surg* adj5 incision*).tw.

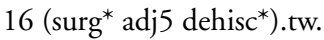

17 (wound* adj5 dehisc*).tw.

18 (wound* adj5 infect*).tw.

19 (wound adj5 disrupt*).tw.

20 wound complication*.tw.

21 or/ $10-20$

22 (intent* $^{*}$ or second* ${ }^{*}$ or heal* or complic*).tw.

23 ((open* or clos*) adj5 wound*).tw.

24 or/ $22-23$

2521 and 24

26 exp Bandages/

27 exp Hydrogels/

28 exp alginic acid/

29 exp Silver/

30 exp Sulfadiazine Silver/

31 exp Honey/

32 (dressing* or hydrocolloid* or alginate* or hydrogel* or foam or bead or film or films or tulle or gauze or non-adherent or non adherent or silver or honey or matrix).tw.

33 or/26-32

349 and 25 and 33

35 Randomized controlled trials/

36 Single-Blind Method/

37 Double-Blind Method/

38 Crossover Procedure/

39 (random* or factorial* or crossover* or cross over* or cross-over* or placebo* or assign* or allocat* or volunteer*).ti,ab.

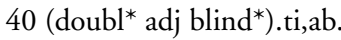

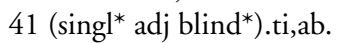

42 or/35-41

43 exp animals/ or exp invertebrate/ or animal experiment/ or animal model/ or animal tissue/ or animal cell/ or nonhuman/

44 human/ or human cell/

45 and $/ 43-44$

4643 not 45

4742 not 46

4834 and 47

\section{EBSCO CINAHL Plus}

\section{S44 S31 AND S43}

S43 S32 or S33 or S34 or S35 or S36 or S37 or S38 or S39 or S40 or S41 or S42

S42 MH "Quantitative Studies"

S41 TI placebo* or AB placebo*

S40 MH "Placebos" Display

S39 TI random* allocat* or AB random* allocat*

S38 MH "Random Assignment"

S37 TI randomi?ed control* trial* or $\mathrm{AB}$ randomi?ed control* trial $^{*}$

S36 AB ( singl* or doubl* or trebl* or tripl* ${ }^{*}$ ) and AB ( blind* or mask* )

S35 TI ( singl* or doubl* or trebl* or tripl* ${ }^{*}$ ) and TI ( blind* or mask*

S34 TI clinic* N1 trial* or AB clinic* N1 trial*

S33 PT Clinical trial

S32 MH "Clinical Trials+"

S31 S9 AND S23 AND S30

S30 S20 OR S21 OR S22 OR S23 OR S24 OR S25 OR S26 OR S27 OR S28 OR S29

Internal dressings for healing perianal abscess cavities (Review)

Copyright () 2016 The Cochrane Collaboration. Published by John Wiley \& Sons, Ltd. 
S29 TI ( (dressing* or alginate* or hydrogel* or hydrocolloid* or foam or bead or film or films or tulle or gauze or non-adherent or non adherent or honey or silver* or matrix) ) OR AB ( (dressing* or alginate* or hydrogel* or hydrocolloid* or foam or bead or film or films or tulle or gauze or non-adherent or non adherent or honey or silver* or matrix) )

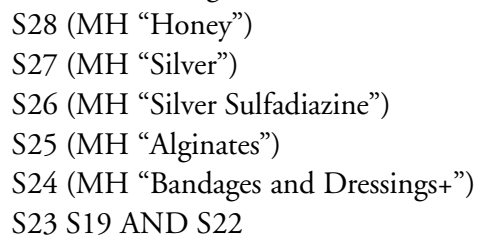

Internal dressings for healing perianal abscess cavities (Review)

Copyright @ 2016 The Cochrane Collaboration. Published by John Wiley \& Sons, Ltd. 
Australia and New Zealand (ANZCTR)

1 abscess

\section{Appendix 2. The Cochrane tool for assessing risk of bias}

\section{Was the allocation sequence randomly generated?}

\section{Low risk of bias}

The investigators describe a random component in the sequence generation process such as: referring to a random number table; using a computer random-number generator; coin tossing; shuffling cards or envelopes; throwing dice; drawing of lots.

\section{High risk of bias}

The investigators describe a non-random component in the sequence generation process. Usually, the description would involve some systematic, non-random approach, for example: sequence generated by odd or even date of birth; sequence generated by some rule based on date (or day) of admission; sequence generated by some rule based on hospital or clinic record number.

\section{Unclear}

Insufficient information about the sequence generation process provided to permit a judgement of low or high risk of bias.

\section{Was the treatment allocation adequately concealed?}

\section{Low risk of bias}

Participants and investigators enrolling participants could not foresee assignment because one of the following, or an equivalent method, was used to conceal allocation: central allocation (including telephone, web-based and pharmacy-controlled randomisation); sequentially numbered drug containers of identical appearance; sequentially numbered, opaque, sealed envelopes.

\section{High risk of bias}

Participants or investigators enrolling participants could possibly foresee assignments and thus introduce selection bias, such as allocation based on: use of an open random allocation schedule (e.g. a list of random numbers); assignment envelopes without appropriate safeguards (e.g. envelopes were unsealed, non-opaque or not sequentially numbered); alternation or rotation; date of birth; case record number; any other explicitly unconcealed procedure.

\section{Unclear}

Insufficient information provided to permit a judgement of low or high risk of bias. This is usually the case if the method of concealment is not described or not described in sufficient detail to allow a definite judgement, for example, if the use of assignment envelopes is described, but it remains unclear whether envelopes were sequentially numbered, opaque and sealed. 


\section{Low risk of bias}

Any one of the following:

- No blinding, but the review authors judge that the outcome and the outcome measurement are not likely to be influenced by lack of blinding.

- Blinding of participants and key study personnel ensured, and unlikely that the blinding could have been broken.

- Either participants or some key study personnel were not blinded, but outcome assessment was blinded and the non-blinding of others is unlikely to introduce bias.

\section{High risk of bias}

Any one of the following:

- No blinding or incomplete blinding, and the outcome or outcome measurement is likely to be influenced by lack of blinding.

- Blinding of key study participants and personnel attempted, but likely that the blinding could have been broken.

- Either participants or some key study personnel were not blinded, and the non-blinding of others is likely to introduce bias.

\section{Unclear risk of bias}

Either of the following:

- Insufficient information provided to permit judgement of low or high risk of bias.

- The study did not address this outcome.

\section{Were incomplete outcome data adequately addressed?}

\section{Low risk of bias}

Any one of the following:

- No missing outcome data.

- Reasons for missing outcome data are unlikely to be related to true outcome (for survival data, censoring unlikely to be introducing bias).

- Missing outcome data are balanced in numbers across intervention groups, with similar reasons for missing data across groups.

- For dichotomous outcome data, the proportion of missing outcomes compared with the observed event risk is not enough to have a clinically relevant impact on the intervention effect estimate.

- For continuous outcome data, a plausible effect size (difference in means or standardised difference in means) among missing outcomes is not enough to have a clinically relevant impact on the observed effect size.

- Missing data have been imputed using appropriate methods.

\section{High risk of bias}

Any one of the following:

- Reason for missing outcome data are likely to be related to the true outcome, with either an imbalance in numbers or reasons for missing data across intervention groups.

- For dichotomous outcome data, the proportion of missing outcomes compared with the observed event risk is enough to induce clinically relevant bias in the intervention effect estimate.

- For continuous outcome data, a plausible effect size (difference in means or standardised difference in means) among missing outcomes is enough to induce clinically relevant bias in the observed effect size.

- 'As-treated' analysis is done with a substantial departure of the intervention received from that assigned at randomisation.

- Potentially inappropriate application of simple imputation. 


\section{Unclear}

Either of the following:

- Insufficient reporting of attrition/exclusions to permit a judgement of low or high risk of bias (e.g. number randomised not stated, no reasons for missing data provided).

- The study did not address this outcome.

\section{Are reports of the study free of suggestion of selective outcome reporting?}

\section{Low risk of bias}

Either of the following:

- The study protocol is available and all of the study's pre-specified (primary and secondary) outcomes that are of interest in the review have been reported in the pre-specified way.

- The study protocol is not available but it is clear that the published reports include all expected outcomes, including those that were pre-specified (convincing text of this nature may be uncommon).

\section{High risk of bias}

Any one of the following:

- Not all of the study's pre-specified primary outcomes have been reported.

- One or more primary outcomes are reported using measurements, analysis methods or subsets of the data (e.g. subscales) that were not pre-specified.

- One or more reported primary outcomes was/were not pre-specified (unless clear justification for their reporting is provided, such as an unexpected adverse effect).

- One or more outcomes of interest in the review is/are reported incompletely so that they cannot be entered in a meta-analysis.

- The study report fails to include results for a key outcome that would be expected to have been reported for such a study.

\section{Unclear}

Insufficient information is provided to permit a judgement of low or high risk of bias. It is likely that the majority of studies will fall into this category.

\section{Other sources of potential bias}

\section{Low risk of bias}

The study appears to be free of other sources of bias.

\section{High risk of bias}

There is at least one important risk of bias. For example, the study:

- had a potential source of bias related to the specific study design used; or

- has been claimed to have been fraudulent; or

- had some other problem.

\section{Unclear}

There may be a risk of bias, but there is either:

- insufficient information to assess whether an important risk of bias exists; or

- insufficient rationale or evidence that an identified problem will introduce bias. 


\section{CONTRIBUTIONSOFAUTHORS}

- Stella Smith: conceived, designed and coordinated the review; extracted data; checked the quality of data extraction; undertook and checked quality assessment; analysed or interpreted data; performed statistical analysis; checked the quality of the statistical analysis; produced the first draft of the review; contributed to writing or editing the review; made an intellectual contribution to the review; approved the final review prior to submission; wrote to study author / experts / companies; and is a guarantor of the review.

- Katy Newton: conceived and designed the review; extracted data; checked the quality of data extraction; analysed or interpreted data; contributed to writing or editing the review; made an intellectual contribution to the review; approved the final review prior to submission; and wrote to study author / experts / companies.

- Jennifer Smith: conceived and designed the review; extracted data; checked the quality of data extraction; analysed or interpreted data; contributed to writing or editing the review; made an intellectual contribution to the review; and approved the final review prior to submission.

- Jo Dumville: conceived and designed the review; extracted data; checked the quality of data extraction; undertook and checked quality assessment; analysed or interpreted data; performed statistical analysis; checked the quality of the statistical analysis; produced the first draft of the review; contributed to writing or editing the review; made an intellectual contribution to the review; and approved the final review prior to submission.

- Zipporah Iheozor-Ejiofor: analysed data; and generated the 'Summary of Findings' table.

- Lyndsay Pearce: conceived and designed the review; contributed to writing or editing the review; made an intellectual contribution to the review; and approved the final review prior to submission.

- Paul Barrow: conceived and designed the review; made an intellectual contribution to the review; and approved the final review prior to submission.

- Laura Hancock: conceived and designed the review; contributed to writing or editing the review; made an intellectual contribution to the review; and approved the final review prior to submission.

- James Hill: conceived and designed the review; contributed to writing or editing the review; made an intellectual contribution to the review; and approved the final review prior to submission.

\section{Contributions of editorial base:}

- Nicky Cullum (Co-ordinating Editor): edited the review, advised on methodology, interpretation and review content, approved the final review prior to publication.

- Gill Rizzello (Managing Editor): coordinated the editorial process, advised on interpretation and content, edited the review prior to publication.

- Reetu Child (Information Specialist) edited the search strategy and the search methods section and ran the searches.

\section{DECLARATIONSOF INTEREST}

The authors S Smith, L Pearce, K Newton, L Hancock, J Smith, P Barrow and J Hill are members of the Packing of Perianal Abscesses Steering Committee - a multicentre observational study of outcomes following incision and drainage of perianal abscesses with the results intended to inform the design of a trial. This study is independent research and not sponsored by industry.

Jo Dumville is funded as part of the National Institute for Health Research Collaboration for Leadership in Applied Health Research and Care (NIHR CLAHRC) Greater Manchester. The views expressed in this article are those of the authors and not necessarily those of the National Health Service (NHS), NIHR, or the Department of Health.

Zipporah Iheozor-Ejiofor- none known.

Internal dressings for healing perianal abscess cavities (Review)

Copyright () 2016 The Cochrane Collaboration. Published by John Wiley \& Sons, Ltd. 


\section{SOURCES OF SUPPORT}

\section{Internal sources}

- Division of Nursing, Midwifery and Social Work, School of Health Sciences, Faculty of Biology, Medicine and Health, University of Manchester, UK.

\section{External sources}

- National Institute for Health Research, UK.

This project was supported by the National Institute for Health Research, via Cochrane Infrastructure and Cochrane Programme Grant funding (NIHR Cochrane Programme Grant 13/89/08 - High Priority Cochrane Reviews in Wound Prevention and Treatment) to Cochrane Wounds. The views and opinions expressed herein are those of the authors and do not necessarily reflect those of the Systematic Reviews Programme, NIHR, National Health Service or the Department of Health

- The National Institute for Health Research Collaboration for Leadership in Applied Health Research and Care (NIHR CLAHRC) Greater Manchester, UK - funding for Jo Dumville, UK.

- The National Institute for Health Research (NIHR Clinical Research Network (CRN)) Portfolio Number 124538, UK.

\section{DIFFERENCES BETWEEN PROTOCOLANDREVIEW}

The text relating to 'Summary of findings' table in the Methods section has been revised to enhance detail. The outcome 'change (and rate of change) in wound size, with adjustment for baseline size' has been moved from the list of primary to secondary outcomes in response to peer review comments.

\section{N D EX TERMS}

\section{Medical Subject Headings (MeSH)}

*Bandages; *Wound Healing; Abscess [* surgery]; Anus Diseases [etiology; *therapy]; Drainage; Postoperative Complications [* therapy]; Randomized Controlled Trials as Topic; Rectal Fistula [etiology; * therapy]; Self Care; Time Factors

\section{MeSH check words}

Humans 